\title{
EL PROCESO INDEPENDENTISTA DE CATALUÑA Y LA DOCTRINA JURISPRUDENCIAL: UNA VISIÓN SISTEMÁTICA
}

\author{
ANTONIO BAR CENDÓN \\ Catedrático de Derecho Constitucional \\ Catedrático Jean Monet "ad personam" \\ Universidad de Valencia
}

\section{SUMARIO}

I. Introducción: los hechos. II. Las resoluciones. III. La doctrina. IV. Conclusiones.

\section{INTRODUCCIÓN: LOS HECHOS}

En los últimos años ${ }^{1}$, se ha producido en Cataluña un movimiento tendente a la consecución de la independencia de esta Comunidad Autónoma española y a su conversión en un «[E]stado catalán independiente en forma de república»². Como consecuencia de este movimiento se ha producido una larga lista de actuaciones de diverso carácter, realizadas por el Parlamento y por el Gobierno de la Generalitat de Cataluña, muchas de las cuales han provocado la actuación del

1 Algunos autores colocan el inicio del actual proceso independentista catalán en la Sentencia del Tribunal Constitucional 31/2010, de 28 de junio, que anuló parte de los preceptos del Estatuto de Cataluña de 2006 (Ley Orgánica 6/2006, de 19 de julio, de reforma del Estatuto de Autonomía de Cataluña) y en la frustración consiguiente provocada en medios políticos. Otros lo localizan en la frustración que causó el fracaso de las negociaciones del Presidente de la Generalitat catalana con el Presidente del Gobierno del Estado por la concesión del «pacto fiscal» a Cataluña, en septiembre de 2012. Aquí, a efectos de centrar el análisis no sólo en la actualidad, sino también en las decisiones jurisdiccionales que afectan directamente a este proceso, entendemos que el mismo se inicia con la Resolución 5/X de 23.1.2013, del Parlamento de Cataluña, por la que se aprueba la declaración de soberanía y del derecho a decidir del pueblo de Cataluña.

2 Resolució 1/XI del Parlament de Catalunya, sobre l'inici del procés polític a Catalunya com a conseqüència dels resultats electorals del 27 de setembre de 2015 (Butlletí Oficial del Parlament de Catalunya, XI legislatura, n. ${ }^{0}$ 7, 9.11.2015, p. 1). 
Gobierno del Estado, de las Cortes Generales, de los tribunales de justicia y del Tribunal Constitucional.

El objetivo de este trabajo es precisamente realizar una ordenación y un análisis sistemáticos de las decisiones adoptadas por el Tribunal Constitucional (en adelante TC) en este proceso y, muy especialmente, de aquellas decisiones — sentencias y autos- que han producido una doctrina constitucional relevante, tanto sobre esta cuestión particular, como con respecto a otras cuestiones relacionadas.

De manera muy resumida, el relato de los hechos que se han producido a lo largo de este tiempo y de los que traen causa las decisiones mencionadas, es el siguiente. En junio de 2006 se publica el nuevo Estatuto de Autonomía de Cataluña (Ley Orgánica 6/2006, de 19 de julio, de reforma del Estatuto de Autonomía de Cataluña), que se presenta como una mera reforma del Estatuto de 1979, cuando, en realidad, se trata de una norma enteramente nueva, mucho más amplia en su número de artículos y en su contenido sustantivo. El nuevo Estatuto fue recurrido por vicios de inconstitucionalidad por noventa y nueve diputados del Partido Popular, pero también por otras entidades legitimadas para ello, como el Consejo de Gobierno de Aragón, el Consejo de Gobierno de las Islas Baleares, la Generailtat Valenciana, el Consejo de Gobierno de Murcia, el Consejo de Gobierno de La Rioja, y el Defensor del Pueblo ${ }^{3}$. La STC 31/2010, de 28 de junio, que resuelve el recurso de inconstitucionalidad interpuesto por los diputados del PP es, sin duda, la más relevante de todas estas decisiones. Es la sentencia más extensa de todas cuantas ha producido el TC hasta la fecha y, sin embargo, su contenido, tanto por el fondo como por la forma, no puede decirse que constituya una de las aportaciones más brillantes de la historia del Tribunal. Más bien al contrario, la sentencia 31/2010 es alambicada, reiterativa y abusa del mecanismo de la interpretación conforme, con la intención de afectar en la menor medida posible el contenido normativo del Estatuto. Es verdad, sin embargo, que el Tribunal hubo de trabajar bajo circunstancias de enorme presión política, en medio de un proceso largamente aplazado de renovación interna, y con la necesidad de decidir ab initio sobre la recusación de cuatro de sus magistrados, teniendo que aceptar la recusación de uno de ellos. Esto también ha podido tener su influencia en la enorme lentitud con la que el TC adoptó su decisión, empleando en ello cuatro años.

La sentencia 31/2010 resultó ser altamente insatisfactoria, tanto para quienes pretendían una revisión más profunda del Estatuto, por ver en el mismo una

3 Véanse las siguientes sentencias del TC: STC 46/2010, que resuelve el recurso de inconstitucionalidad interpuesto por el Consejo de Gobierno de Aragón; STC 47/2010, que resuelve el recurso de inconstitucionalidad interpuesto por el mismo motivo por el Consejo de Gobierno de las Islas Baleares; STC 48/2010, que resuelve el recurso de inconstitucionalidad interpuesto por la Generailtat Valenciana; STC 49/2010, que resuelve el recurso de inconstitucionalidad interpuesto por el Consejo de Gobierno de Murcia; la STC 137/2010, que resuelve el recurso de inconstitucionalidad interpuesto por el Defensor del Pueblo; y STC 138/2010, que resuelve el recurso de inconstitucionalidad interpuesto por el Consejo de Gobierno de La Rioja. 
reforma implícita de la Constitución, como para quienes sostenían que el TC debería haberse autolimitado más —o, incluso, haberse abstenido— en su actuación por cuanto el Estatuto había sido sometido ya a referéndum de los ciudadanos de Cataluña. La sentencia 31/2010, pues, fue entonces — y sigue siendo ahora, en buena medida - la excusa para el inicio de una enorme movilización política de carácter identitario ${ }^{4}$. Por otra parte, el gran malestar social existente entonces, producido por las restricciones financieras y las duras medidas adoptadas como consecuencia de la crisis económica del momento, tanto en Cataluña como en el conjunto de España, permitió añadir leña al fuego y culpabilizar al Gobierno central y a la dependencia de Cataluña del Estado de la grave situación que se vivía. Así, la dependencia económica y fiscal de Cataluña con respecto al Estado fue añadida inmediatamente a la a la cuestión identitaria como motivo y justificación de la exigencia de independencia para Cataluña. De hecho, un nuevo sistema de financiación autonómica y, más específicamente, un «pacto fiscal» similar al del País Vasco o de Navarra, fue la exigencia inexcusable que el Gobierno de la Generalitat presentó al Gobierno central en la reunión que el Presidente de la Generalitat catalana, Artur Mas, y el Presidente del Gobierno de España, Mariano Rajoy, mantuvieron en la Moncloa, el 20 de septiembre de 2012. La negativa del Gobierno central a ceder a esta exigencia, por entender que ello sería contrario a la Constitución, fue la excusa para el inicio de este este proceso, planteado en términos escalonados, progresivos, que debería llevar finalmente a la independencia de Cataluña.

Así, el 27 de septiembre de 2012, el Parlamento de Cataluña aprobaba su Resolución 742/IX en la que se decía que "Catalunya ba d'iniciar una nova etapa basada en el dret de decidir» (Cataluña debe iniciar una nueva etapa basada en el derecho a decidir) y se instaba al nuevo Gobierno que habría de salir de las elecciones autonómicas que se iban a realizar el 25 de noviembre de ese año, «a fer una consulta, prioritàriament dins la pròxima legislatura» (a realizar una consulta, prioritariamente en la próxima legislatura); en fin, el Parlamento catalán proclamaba solemnemente «el dret imprescriptible $i$ inalienable de Catalunya a l'autodeterminació, com a expressió democràtica de la seva sobirania com a nació» (el derecho imprescriptible e inalienable de Cataluña a la autodeterminación, como expresión democrática de su soberanía como nación) $)^{5}$. Y, efectivamente, el nuevo Gobierno salido de aquellas elecciones no tardaría en hacer su propuesta; así el 23 de enero de 2013 el Parlamento aprobaba la Resolució 5/X del Parlament de Catalunya, per la qual s'aprova la Declaració de sobirania i del dret a decidir del poble de Catalunya (Declaración de soberanía y del derecho a decidir del pueblo de Cataluña $)^{6}$. Se

4 «Som una nació» fue el lema de la enorme manifestación que se organizó en Barcelona en contra de la sentencia del TC, el 10 de julio de 2010, y también el de la fiesta de Cataluña que se celebró el 11 de septiembre siguiente.

5 Butlletí Oficial del Parlament de Catalunya, n. ${ }^{\circ} 390,2.10 .2012$.

6 Butlletí Oficial del Parlament de Catalunya, n. ${ }^{\circ} 13,24.1 .2013$. 
daba de esta manera un importante paso hacia delante en este proceso, que el Gobierno — que había permanecido inactivo ante la anterior Resolución- no pudo dejar pasar sin respuesta. La impugnación por el Gobierno de la Resolución 5/X ante el TC se produjo el 8 de marzo y, con ello, se abría la serie de actuaciones de carácter jurisdiccional de las que se ocupa este trabajo, por lo que se deja para más adelante el estudio de esta cuestión.

Con la intención de dar una mayor solidez a su reivindicación, la Generalitat catalana creó en febrero de 2013 el Consell Assessor per a la Transició Nacional, presidido por Carles Viver i Pi-Sunyer, antiguo magistrado del Tribunal Constitucional español ${ }^{7}$. Este órgano llegaría a producir dieciocho informes sobre diversos aspectos de la historia, la economía, las relaciones internacionales, la organización y el futuro político de Cataluña. Estos informes son hoy el sostén dogmático sobre el que se asienta el proceso independentista.

En septiembre de 2013, el Parlamento catalán, si bien insiste en el «derecho a decidir» como objetivo fundamental de su actuación, se manifiesta un poco más dialogante y propone el establecimiento de un diálogo para conseguir del Congreso de los Diputados y del Presidente del Gobierno la apertura de las vías necesarias para autorizar la celebración de un «referèndum sobre el futur polític de Catalunya» a lo largo del año 2014, al mismo tiempo que insta al Gobierno autonómico a seguir con las actuaciones necesarias para la preparación del mencionado referéndum ${ }^{8}$. En cumplimiento del mandato parlamentario, pero adelantándose a la apertura del mencionado diálogo, en diciembre de 2013, el Presidente Mas anunciaría la fecha de la consulta — el 9 de noviembre de 2014 - y la doble pregunta a formular a los ciudadanos: «¿Desea usted que Cataluña se convierta en un Estado?» $\mathrm{y}$ «si está de acuerdo, ¿desea usted que Cataluña sea un Estado independiente?».

El 21 de enero de 2014 tenía entrada en el Congreso de los Diputados una proposición de Ley Orgánica de delegación en la Generalidad de Cataluña de la competencia para autorizar, convocar y celebrar un referéndum sobre el futuro político de Cataluña, en la que se proponía que esta competencia estatal fuese delegada en el Gobierno de la Generalidad y que el referéndum fuese convocado antes de que finalizase el año 2014․ El Congreso de los Diputados, sin embargo, rechazaría la proposición en abril de 2014, por una amplia mayoría ${ }^{10}$. Y sólo unas semanas antes, el TC haría pública su primera decisión importante en este terreno, la STC 42/2014, de 25 de marzo, que anularía la Resolución del Parlamento

7 Decret 113/2013, de 12 de febrer, de creació del Consell Assessor per a la Transició Nacional (Diari Oicial de la Generalitat de Catalunya, n. ${ }^{\circ} 6315,14.2 .2013$, p. 8187).

8 Resolució 323/X del Parlament de Catalunya, sobre l'orientació política general del Govern (Butlletí Oficial del Parlament de Catalunya, n. ${ }^{\circ}$ 160, 2.10.2013.

9 Boletín Oficial de las Cortes Generales. Congreso de los Diputados, Serie B, n. ${ }^{\circ}$ 158-1, 24.1.2014.

10 El resultado fue: 299 votos en contra, 47 a favor y una abstención (Diario de Sesiones del Congreso de los Diputados. Pleno y Diputación Permanente. X Legislatura. Núm. 192. Sesión plenaria núm. 180, 8 de abril de 2014). 
de Cataluña 5/X, de 23 de enero de 2013. Las vías para el supuesto diálogo quedaban así formalmente cerradas, dado que la pretensión última de la Generalitat, el ejercicio del derecho a la autodeterminación — como lo había definido, en sus propios términos, la Resolución 742/IX, de 2012, del Parlamento catalán- es irreconciliable con la Constitución de 1978, en su redacción actual.

En desarrollo del plan previsto, el Parlamento de Cataluña aprobó, en septiembre de 2014, la Ley 10/2014, de 26 de septiembre, de consultas populares no referendarias y otras formas de participación ciudadana ${ }^{11}$, y un día después el Presidente Mas publicó el Decreto de convocatoria de la consulta (Decreto 129/2014, de 27 de septiembre, del Presidente de la Generalitat de convocatoria de una consulta popular no referendaria). Tanto la Ley como el Decreto tratan ahora de soslayar la colisión con la regulación constitucional del referéndum consultivo y cambian la denominación de la consulta a convocar, que pasa a ser denominada, de manera explícita, «consulta popular no referendaria». El Gobierno del Estado, sin embargo, recurrió ante el TC ambas normas, que fueron inmediatamente suspendidas por el Tribunal, en aplicación de las previsiones del artículo 161.2 de la Constitución. En última instancia, las sentencias del TC 31/2015 y 32/2015 pondrían fin a la existencia formal de ambas normas, el 25 de febrero de 2015.

La suspensión de la Ley de consultas y del Decreto de convocatoria privaba al Gobierno catalán de la posibilidad de realizar una consulta formal, en los términos y con las garantías allí previstas, con lo que éste decidió sortear el obstáculo mediante la convocatoria de una consulta que pasa a denominar «proceso de participación ciudadana», y que anuncia el día 14 de octubre, abriendo una página web al efecto. La nueva consulta era convocada para el día 9 de noviembre de 2014. La actuación de la Generalitat, si bien desoye la suspensión de la Ley de consultas y del Decreto de convocatoria, se cuida de no dar a este «proceso de participación ciudadana» la apariencia jurídico-formal que permitiese considerarlo verdaderamente una «consulta popular no referendaria», tal y como ésta era regulada en la normativa entonces sólo suspendida. Sin embargo, el Gobierno decidió impugnar una vez más todas las actuaciones de la Generalitat a este respecto, cosa que hizo el día 31 de octubre de 2014, siendo estas actuaciones suspendidas por providencia del TC el 4 de noviembre, cinco días antes de la consulta.

La impugnación de estas actuaciones de la Generalitat, conducentes a la realización de la consulta del 9 de noviembre, entrañaba ciertos riesgos, dado que las medidas adoptadas carecían de la apariencia jurídico-formal — habitual- necesaria para su impugnabilidad, pues eso era precisamente lo que había buscado el Gobierno de la Generalitat. Ello iba a forzar al TC a realizar una interpretación ciertamente novedosa o, quizá, muy forzada del carácter de las medidas adoptadas, a fin de poder considerarlas idóneas para ser impugnadas a través del cauce 
constitucional previsto al efecto. En este sentido, cabría decir que, en vez de utilizar el papel tradicional, la Generalitat utilizaba los medios electrónicos de información y comunicación más modernos para la organización y convocatoria de este «proceso de participación ciudadana», y aquí se encontraba la dificultad procesal.

En realidad, las medidas adoptadas por la Generalitat e impugnadas por el Gobierno fueron las siguientes: creación de una página web (www.participa2014. cat) que incluía un contenido muy detallado y exhaustivo de todos los aspectos de la convocatoria de la consulta; comunicaciones oficiales dirigidas por la Generalitat — mediante correo electrónico- a distintas entidades jurídico-públicas, como entidades locales o centros educativos, en las que se les requería su colaboración y el uso de sus locales; publicación en el «Diario Oficial de la Generalitat de Cataluña», de 16 de octubre de 2014, de un edicto de información pública, adicionando un fichero en el que se podían inscribir voluntariamente los ciudadanos que deseasen participar en la consulta; requerimiento, mediante un correo electrónico, a todos los medios de comunicación con licencia para emitir en Cataluña, para que emitiesen gratuitamente y con indicación de su origen las comunicaciones y declaraciones que la Generalitat considerase convenientes, en aplicación del artículo 82 de la Ley de comunicación audiovisual de Cataluña; e inicio el día 31 de octubre de 2014 de una campaña publicitaria de la celebración de la consulta mediante la inserción de anuncios en medios de comunicación.

Sin embargo, por providencia de 4 de noviembre, el TC admitió a trámite la impugnación del Gobierno y ordenó la inmediata suspensión de la consulta del 9 de noviembre — «proceso de participación ciudadana»— y de todas las actuaciones de la Generalitat catalana relacionadas.

En el medio de este proceso, en un giro peculiar en su estrategia procesal, la Generalitat decidió entonces acudir al Tribunal Supremo, Sala de lo Contencioso-Administrativo, y recurrir inaudita parte el acuerdo del Consejo de Ministros, del 31 de octubre de 2014, de impugnar ante el TC las mencionadas actuaciones de la Generalidad relativas a la convocatoria del 9 de noviembre. En dos autos consecutivos, primero en el procedimiento inaudita parte - Auto 9126/2014, de 6 de noviembre-, y después en procedimiento abierto ya a las alegaciones de las partes - Auto 10383/2014, de 27 de noviembre-, el Tribunal Superno inadmitió el recurso contencioso-administrativo interpuesto por la Generalidad no sólo por apreciar su falta de jurisdicción en la materia, sino porque el recurso fue presentado ante el Tribunal Supremo cuando el Gobierno ya había presentado su impugnación ante el TC y éste la había admitido a trámite.

En todo caso, en manifestación de clara rebeldía frente a la decisión del TC de suspender las actuaciones referidas, la Generalitat siguió adelante con la convocatoria y ésta se celebró sin contratiempo notable el día previsto, el 9 de noviembre de 2014. El resultado no fue muy brillante, dado que — según los datos de la propia Generalitat_- si bien el 80,7\% de los participantes en la consulta votó a favor del establecimiento de un Estado catalán independiente, la partici- 
pación fue sólo del $36,59 \%$, sobre el censo no oficial elaborado al efecto, el cual, por otra parte, incluía la participación de mayores de dieciséis años, de nacionales de Estados miembros de la Unión Europea, y de nacionales de terceros Estados, inscritos en el Registro de Población de Cataluña ${ }^{12}$. En fin, el TC declararía inconstitucional todo el «proceso de participación ciudadana» del 9 de noviembre de 2014 por su sentencia 138/2015, de 11 de junio.

El aparente fracaso de la convocatoria del 9 de noviembre de 2014, en lo que se refiere precisamente a la participación ciudadana, no frenó el proceso independentista, en términos generales, muy al contrario, en febrero de 2015, la Generalitat creó el Comisionado para la Transición Nacional; un cargo que se adscribe al Departamento de la Presidencia, con el objetivo de formular propuestas, dar impulso y coordinar las medidas y actuaciones preparatorias de la creación de las estructuras de Estado (Decreto de la Generalitat 16/2015, de 24 de febrero, por el que se crea el Comisionado para la Transición Nacional). Sin embargo, una vez más, el Gobierno de España salió al paso de esta medida y, tras requerir a la Generalitat, planteó ante el TC un conflicto positivo de competencia el 26 de junio de 2015; conflicto que se extendió no sólo al mencionado Decreto 16/2015 de la Generalitat, sino también contra los denominados Plan Ejecutivo para la Preparación de las Estructuras de Estado y Plan de Infraestructuras Estratégicas, así como frente a las previsiones y las actuaciones desarrolladas en aplicación o al amparo de dicho Decreto o de los referidos planes. El TC admitió a trámite el conflicto y ordenó la suspensión de las medidas cuestionadas (providencia de 7 de julio de 2015). El TC se pronunciaría sobre el fondo de esta cuestión en el marco de la STC 259/2015, de 2 de diciembre, de la que nos ocupamos más adelante.

Finalmente la cima de este proceso se va a alcanzar cuando, tras las elecciones autonómicas del 27 de septiembre de 2015, los partidos separatistas consiguen la mayoría en el Parlamento catalán (53,3\% de los escaños), en unas elecciones que el Presidente Mas había convocado con carácter plebiscitario (como alternativa al nunca realizado referéndum sobre la cuestión nacional) y que, paradójicamente, perdieron en términos de votación absoluta, dado que sólo consiguieron el 47,8\% de los votos. Esta situación de poder en el Parlamento, llevó a los grupos separatistas a presentar ante la Mesa del Parlamento, primero, y a aprobar en el Pleno después, la Resolución 1/XI, de 9 de noviembre de 2015, del Parlamento de Cataluña, sobre el inicio del proceso político en Cataluña. Esta Resolución - sobre la que se volverá más adelante- es verdaderamente, hasta el presente, la actuación más radical realizada por el Parlamento de Cataluña, dado que en ella el Parlamento «declara solemnemente el inicio del proceso de creación de un estado catalán independiente en forma de república» (punto segundo) y, en este sentido, "proclama la apertura de un proceso constituyente ciudadano, participativo, abierto, integrador y activo para preparar las bases de la futura constitución cata-

12 Vid. http://www.participa2014.cat/resultats/dades/es/escr-tot.html 
lana» (punto tercero). La resolución fue impugnada por el Gobierno de España el 11 de noviembre, y el TC la admitió a trámite y ordenó su suspensión mediante providencia de la misma fecha. El TC, además, ordenó la notificación personal de la providencia a la Presidenta del Parlamento de Cataluña, a cada uno de los miembros de la Mesa, al Secretario General de la Cámara, y al Presidente y demás miembros del Consejo de Gobierno de la Generalitat — entonces en funciones-, apercibiéndoles de las eventuales responsabilidades en las que incurrirían, incluida la penal, en caso de ignorar la suspensión. El TC ejercía así, por primera vez, las competencias controladoras de la ejecución de sus propias resoluciones y sancionadoras, que le atribuye la nueva redacción de los artículos 87 y 92 de su Ley Orgánica dada por la Ley Orgánica 15/2015, de 16 de octubre, de reforma de la Ley Orgánica 2/1979, de 3 de octubre, del Tribunal Constitucional, para la ejecución de las resoluciones del Tribunal Constitucional como garantía del Estado de Derecho, que acababa de entrar en vigor.

El trámite parlamentario de la Resolución 1/XI, de 9 de noviembre de 2015, del Parlamento de Cataluña, sobre el inicio del proceso político en Cataluña, dio lugar a la presentación de recursos de amparo contra la decisión de la Mesa del Parlamento de admitir a trámite la propuesta de resolución y la desestimación de la solicitud de reconsideración del mencionado acuerdo, presentados por diputados del Grupo Parlamentario de Ciudadanos, del Grupo del PP y del Grupo Parlamentario Socialista. Los parlamentarios de Ciudadanos y del PP, además, solicitaron del TC la suspensión del debate parlamentario de la mencionada resolución. El TC, mediante los autos y las providencias que se mencionan más adelante, admitió a trámite los recursos de amparo presentados, pero inadmitió la solicitud de suspensión pedida por los parlamentarios de Ciudadanos y del PP. Ello, por consiguiente, permitió el debate parlamentario y la aprobación de la resolución mencionada.

Finalmente, este proceso y las actuaciones jurisdiccionales correlativas se cierra con la sentencia del TC 259/2015, de 2 de diciembre, que anula en su totalidad la Resolución 1/XI, de 9 de noviembre de 2015, del Parlamento de Cataluña ${ }^{13}$.

13 Cuando este artículo había sido ya entregado a la imprenta, se produjo la formación del nuevo Gobierno de la Generalitat, de Carles Puigdemont. La estructura del nuevo Gobierno catalán incluía la creación del Departamento de Asuntos Exteriores, Relaciones Institucionales y Transparencia, por los Decretos de la Generalitat 2/2016, de 13 de enero, de creación, denominación y determinación del ámbito de competencia de los departamentos de la Administración de la Generalidad de Cataluña, y 45/2016, de 19 de enero, de estructuración del Departamento de Asuntos Exteriores, Relaciones Institucionales y Transparencia. El 16 de febrero, el Gobierno del Estado presentó un conflicto positivo de competencia contra estos decretos de la Generalitat catalana, por entender que invadían la competencia exclusiva del Estado en materia de relaciones exteriores (art. 149.1.3 $3^{\mathrm{a}}$ de la Constitución), y el recurso fue admitido a trámite por el TC, que ordenó también la suspensión de los preceptos impugnados (Auto de 16 de febrero de 2016). Además, en la misma fecha, el TC acordó también admitir a trámite el incidente de ejecución de sentencia presentado por el Gobierno contra la decisión del Parlamento de Cataluña de crear una comisión de estudio del proceso constituyente, dando un plazo de diez días al Ministerio Público y al Parlamento catalán para presentar sus escritos. (Providencia de 16 de febrero de 2016). 


\section{LAS RESOLUCIONES}

Este proceso independentista — como se decía en páginas anteriores- ha provocado la sustanciación de una larga serie de procedimientos y de decisiones jurisdiccionales, algunas de las cuales han sido mencionadas ya. En total, son 23 las resoluciones adoptadas por el TC a lo largo de estos años, desde que se produjo el recurso de noventa y nueve diputados del PP en contra del Estatuto de Autonomía de Cataluña de 2006. De estas resoluciones, 13 son autos razonados o fundamentados, y 10 son sentencias ${ }^{14}$. A ello habría que añadir un número aún más elevado de providencias, algunas de las cuales han sido también fundamentadas con cierta extensión. Y, desde luego, cabría aún añadir a esta lista los dos autos del Tribunal Supremo, de octubre y noviembre de 2014, recaídos en el recurso presentado por la Generalitat contra la legitimación del Gobierno para poder recurrir al TC las actuaciones de la Generalitat conducentes a la celebración de la consulta — «proceso de participación ciudadana»— del 9 de noviembre de 2014. Sin embargo, y para no reproducir aquí una lista de actos jurisdiccionales demasiado larga, se enumeran a continuación sólo aquellas decisiones que tienen relevancia desde el punto de vista de su contenido material-constitucional, o de fijación de doctrina, y que, por ello, son estudiadas en este trabajo. La lista que sigue, pues, ordena estas decisiones de forma sistemática en función de la actuación impugnada o recurrida, y — como queda dicho— menciona sólo aquellas decisiones jurisdiccionales — autos y sentencias - que tienen una mayor relevancia doctrinal sobre las materias en cuestión. Estas decisiones son las siguientes:

a) Impugnación por el Gobierno de la Resolución 5/X, de 23.1.2013, del Parlamento de Cataluña, por la que se aprueba la declaración de soberanía y del derecho a decidir del pueblo de Cataluña: ATC 156/2013, de 11 de julio de 2013, mantiene la suspensión de la Resolución 5/X, de 23 de enero de 2013, del Parlamento de Cataluña, por la que se aprueba la declaración de soberanía del pueblo de Cataluña. STC 42/2014, de 25 de marzo, sobre la resolución 5/X, de 23 de enero de 2013, del Parlamento de Cataluña, por la que se aprueba la declaración de soberanía del pueblo de Cataluña.

b) Recurso de inconstitucionalidad n. ${ }^{\circ}$ 5829-2014, del Presidente del Gobierno contra la Ley de Cataluña 10/2014, de 26 de septiembre, de consultas populares no referendarias y otras formas de participación ciudadana: STC 31/2015, de 25 de febrero, sobre la Ley de Cataluña 10/2014, de 26 de septiembre, de consultas populares no referendarias y otras formas de participación ciudadana.

c) Impugnación del Gobierno núm.5830-2014 contra Decreto 129/2014 de 27 de septiembre, del Presidente de la Generalitat de Cataluña, de convocatoria de una

14 A estas actuaciones deberían ser añadidas las mencionadas en la nota anterior, de fecha de 16 de febrero de 2016, que no son aquí analizadas.

UNED. Teoría y Realidad Constitucional, núm. 37, 2016, pp. 187-220 
consulta popular no referendaria: STC 32/2015, de 25 de febrero, sobre el Decreto 129/2014, de 27.9.2014, del Presidente de la Generalitat de convocatoria de una consulta popular no referendaria.

d) Impugnación del Gobierno contra las actuaciones relativas a la convocatoria de la consulta del 9 Noviembre de 2014, «proceso de participación ciudadana»: ATC 292/2014, de 2 de diciembre, desestima el recurso de súplica interpuesto por la Generalitat contra la Providencia del TC, de 4.11.2013, por la que se admite a trámite la impugnación de las actuaciones relativas a la convocatoria del denominado «proceso de participación ciudadana», del 9 de noviembre de 2014. STC 138/2015, de 11 de junio, sobre la impugnación por el Gobierno de las actuaciones relativas a la convocatoria de la consulta del 9 Noviembre, "proceso de participación ciudadana». Las declara inconstitucionales.

e) Tribunal Supremo, Sala de lo Contencioso-Administrativo: Recurso contencioso-administrativo interpuesto por la Generalidad de Cataluña contra el acuerdo del Consejo de Ministros, de 31 de octubre de 2014, de impugnar ante el TC las actuaciones de la Generalidad relativas a la convocatoria del 9 de noviembre de 2014: Auto TS 9126/2014, de 6 de noviembre, que inadmite el recurso contencioso-administrativo interpuesto por la Generalidad de Cataluña, inaudita parte, contra el acuerdo del Consejo de Ministros de 31.10.2014 por el que se decide impugnar ante el Tribunal Constitucional las actuaciones de la Generalidad de Cataluña relativas a la convocatoria del 9 de noviembre de 2014. Auto TS 10383/2014, de 27 de noviembre, que inadmite el recurso contencioso-administrativo interpuesto por la Generalidad de Cataluña contra el acuerdo del Consejo de Ministros de 31.10.2014 por el que se decide impugnar ante el Tribunal Constitucional las actuaciones de la Generalidad de Cataluña relativas a la convocatoria del 9 de noviembre de 2014.

f) Conflicto positivo de competencia contra el Decreto de la Generalitat 16/2015, de 24 de febrero, por el que se crea el Comisionado para la Transición Nacional; contra el Pan Ejecutivo Para la Preparación de las Estructuras de Estado; y contra el Plan de Infraestructuras Estratégicas: ATC 186/2015, de 3 de noviembre, sobre el conflicto positivo de competencias planteado por el Gobierno contra el Decreto de la Generalitat 16/2015, de 24 de febrero, por el que se crea el Comisionado para la Transición Nacional; contra el Pan Ejecutivo Para la Preparación de las Estructuras de Estado; contra el Plan de Infraestructuras Estratégicas; y contra las actuaciones desarrolladas en aplicación del Decreto y de los Planes.

g) Recursos de amparo contra acuerdos de la Mesa del Parlamento de Cataluña de 27, 28 de octubre de 2015, y 2 y 3 de noviembre de 2015, referidos a la admisión a trámite de la propuesta de Resolución 1/XI, de 9 de noviembre de 2015, sobre el inicio del proceso político en Cataluña: ATC 189/2015, de 5 de noviembre, sobre la solicitud — presentada por diputados del Grupo de Ciudadanos 
del Parlamento de Cataluña - de suspensión de los acuerdos de la Mesa del Parlamento de Cataluña de 27 de octubre 2015, de admitir a trámite la propuesta de resolución sobre el inicio del proceso político en Cataluña; y el acuerdo de la Mesa de 3 de noviembre de 2015 por el que se desestima la solicitud de reconsideración del mencionado acuerdo, formulados por los Grupos Parlamentarios de C's y PSC. ATC 190/2015, de 5 de noviembre, sobre la solicitud de suspensión —que acompaña a los recursos de amparo de varios diputados del PP del Parlamento de Cataluña- de los acuerdos de la Mesa del Parlamento de Cataluña de 27 de octubre de 2015, de admitir a trámite la propuesta de resolución sobre el inicio del proceso político en Cataluña; del acuerdo de la Mesa de 28 de octubre de 2015, por el que se acuerda la tramitación de la citada propuesta por el procedimiento de urgencia; del acuerdo de la Mesa de 2 de noviembre de 2015, de convocar la Junta de Portavoces para el día siguiente; y de los acuerdos de la Mesa de 3 de noviembre de 2015, por los que se desestiman los escritos de petición de reconsideración de los mencionados acuerdos, formulados por los Grupos Parlamentarios del PP, C's y PSC.

h) Impugnación del Gobierno n. ${ }^{\circ}$ 6330-2015, contra la Resolución 1/XI, de 9 de noviembre de 2015, del Parlamento de Cataluña, sobre el inicio del proceso politico en Cataluña: STC 259/2015, de 2 de diciembre, sobre la Resolución 1/XI, de 9 de noviembre de 2015, del Parlamento de Cataluña, sobre el inicio del proceso político en Cataluña.

Desde luego, a las decisiones aquí enumeradas, pueden ser añadidas las producidas como producto de incidentes de recusación de magistrados del TC que han tenido lugar con motivo de (a) la impugnación por el Gobierno del Estado de la Resolución 5/X, de 23 de enero de 2013, del Parlamento de Cataluña, por la que se aprueba la declaración de soberanía y del derecho a decidir del pueblo de Cataluña; y (b) el recurso de inconstitucionalidad n. ${ }^{\circ}$ 5829-2014, del Presidente del Gobierno contra la Ley de Cataluña 10/2014, de 26 de septiembre, de consultas populares no referendarias y otras formas de participación ciudadana. Incidentes resueltos, en el primer caso, por el Auto del TC 180/2013, de 17 de septiembre, que inadmite las recusaciones del Presidente del TC promovidas en una larga lista de procedimientos constitucionales y, entre ellos, la impugnación n. ${ }^{\circ}$ 1389-2013 contra la Resolución 5/X del Parlamento de Cataluña; y, en el segundo caso, por los Autos del TC 237/2014 y 238/2014, de 9 de octubre, que inadmiten la recusación del Presidente del TC, Francisco Pérez de los Cobos, y del Magistrado Pedro González-Trevijano. En todos los casos, el TC es prolijo en sus argumentaciones, que perfilan en términos doctrinales el incidente de recusación, sin embargo, este tipo de procedimiento tiene una relevancia adjetiva, muy marginal en relación con la sustancia de este trabajo y, por ello, no son aquí analizados. 
Por otra parte, existe también otra serie de decisiones jurisdiccionales que se encuentran materialmente relacionadas con las aquí analizadas, sin embargo, el hecho de que no se refieran de manera directa y específica al momento del proceso independentista aquí estudiado nos obliga a dejarlas a un lado en este momento, de lo contrario este estudio se haría interminable.

Entre estas decisiones se encuentra, en un lugar muy destacado, la sentencia del TC 31/2010, de 28 de junio, que resuelve el recurso de inconstitucionalidad interpuesto por noventa y nueve diputados del PP contra el Estatuto de Cataluña de 2006. Sentencia que — como se ha dicho en páginas anteriores — no sólo es la más extensa de la historia del TC (491 pp. del BOE), sino que abarca una amplia lista de cuestiones de relevancia constitucional, tales como el propio concepto de «Estatuto de Autonomía»; el fundamento jurídico-político del Estatuto y de los poderes del gobierno autonómico; el valor jurídico del Preámbulo; el concepto de nación; los denominados «derechos históricos»; los derechos y deberes de los ciudadanos; el derecho y el deber de utilizar el castellano y el idioma propio de la Comunidad Autónoma, así como la enseñanza de ambas leguas; las instituciones de la Comunidad Autónoma; la convocatoria de consultas populares; el Derecho Civil propio; las relaciones de la Comunidad Autónoma con el Estado, con otras Comunidades y con la Unión Europea; la acción exterior de la Comunidad; la financiación de la Comunidad; y, en fin, la reforma del Estatuto. Temas, todos ellos, que — junto con la cuestión de procedibilidad—, como se verá a continuación, seguirán siendo los asuntos controvertidos de los que se ocupan, de manera central, las decisiones jurisdiccionales adoptadas durante el período histórico que aquí se analiza ${ }^{15}$.

La sentencia del TC 31/2010, además, vino precedida por una serie de pronunciamientos del Tribunal sobre las recusaciones de varios Magistrados que fueron presentadas por las partes en el proceso. El alto número de recusaciones presentadas, en una y otra dirección, más determinadas por cuestiones políticas que por verdaderos motivos sustanciales de recusación, da una idea muy clara de la alta conflictividad política que condicionó la decisión final del Tribunal, en el asunto sustantivo de fondo y en esta cuestión de carácter adjetivo. Así, el Auto del TC 383/2006, de 2 de noviembre, por el que el Pleno del Tribunal acordó inadmitir la recusación de la Magistrada y Presidenta del TC, María Emilia Casas Baamonde, presentada por los parlamentarios del PP, por considerar la concurrencia de la causa prevista en el artículo 219.14 LOPJ, en relación con la segunda del mismo precepto legal (Auto que dio lugar al voto particular concurrente del Magistrado Jorge Rodríguez-Zapata); el ATC 394/2006, de 7 de noviembre,

15 La sentencia 31/2010, por otra parte, ha sido abundantemente analizada por la doctrina científica desde el mismo momento de su publicación, lo que nos libera del deber de hacerlo aquí. Véase, por todos, los tempranos trabajos contenidos en el número de la Revista Catalana de Dret Públic, Especial Sentència 31/2010 del Tribunal Constitucional, sobre l'Estatut d'autonomia de Catalunya de 2006 (Barcelona, Escola d'Administració Pública de Catalunya, 2010), coordinado por Mercè Barceló, Xavier Bernadí y Joan Vintró. 
que inadmite la recusación del Magistrado don Roberto García-Calvo, presentada por el Gobierno de la Generalitat y el Parlamento de Cataluña, por hallarse incurso en las causas 10,11 y, subsidiariamente, 16 del artículo 219 LOPJ (Auto que dio lugar al voto particular concurrente la Magistrada Elisa Pérez Vera); el ATC 26/2007, de 5 de febrero, que estima la recusación formulada por los diputados del PP, del Magistrado Pablo Pérez Tremps, por apreciar la concurrencia de las causas de recusación 6, 10,13 y 16 del artículo 219 LOPJ, en relación con el artículo 80 LOTC (Auto que dio lugar a los votos particulares concurrentes de los Magistrados Conde Martín de Hijas y Rodríguez-Zapata, y los votos particulares discrepantes de la Presidenta del TC, María Emilia Casas, y los Magistrados Pérez Vera, Gay Montalvo, Sala Sánchez y Aragón Reyes); el ATC 192/2007, de 21 de marzo, que declara inadmisible el recurso de súplica presentado por la Generalitat contra el referido ATC 26/2007, de 5 de febrero (Auto que dio lugar a los votos particulares concurrente de la Presidenta del TC, María Emilia Casas, y los Magistrados Elisa Pérez Vera, Eugeni Gay Montalvo, Pascual Sala Sánchez, Manuel Aragón Reyes y Roberto García-Calvo y Montiel); el ATC 177/2007, de 7 de marzo, por el que el Pleno inadmitió la recusación del Magistrado Jorge Rodríguez-Zapata, presentada por la Generalitat de Cataluña, por incurrir en la causa prevista en el artículo 219.13 LOPJ; y el ATC 224/2007, de 19 de abril, que desestima el recurso de súplica interpuesto por el Gobierno de la Generalitat de Cataluña contra el mencionado ATC 177/2007, de 7 de marzo.

La sentencia del TC 31/2010, de 28 de junio, en fin, vino seguida por otra serie de sentencias que resolvieron los consiguientes recursos de inconstitucionalidad contra el el Estatuto de Autonomía de Cataluña de 2006. Así, la STC $46 / 2010$, que resuelve el recurso de inconstitucionalidad interpuesto por el Consejo de Gobierno de Aragón; la STC 47/2010, que resuelve el recurso de inconstitucionalidad interpuesto por el Consejo de Gobierno de las Islas Baleares; la STC 48/2010, que resuelve el recurso de inconstitucionalidad interpuesto por la Generailtat Valenciana; la STC 49/2010, que resuelve el recurso de inconstitucionalidad interpuesto por el Consejo de Gobierno de Murcia; la STC 137/2010, que resuelve el recurso de inconstitucionalidad interpuesto por el Defensor del Pueblo; y la STC 138/2010, que resuelve el recurso de inconstitucionalidad interpuesto por el Consejo de Gobierno de La Rioja.

Como conclusión, merece la pena mencionar en este apartado dos actuaciones del TC que se refieren de manera específica a la controvertida cuestión de la convocatoria de consultas populares por las Comunidades Autónomas: una previa a los hechos aquí descritos y referida al País Vasco, que es mencionada en la jurisprudencia aquí analizada; y otra coetánea a las decisiones referidas a Cataluña aquí analizadas y que, por tanto, no es mencionada por el TC en sus decisiones referidas a la cuestión catalana.

La primera de ellas es la STC 103/2008, de 11 de septiembre, sobre el recurso de inconstitucionalidad n. ${ }^{\circ}$ 5707-2008, interpuesto por el Presidente del Gobierno contra la Ley del Parlamento Vasco 9/2008, de 27 de junio, de convocato- 
ria y regulación de una consulta popular al objeto de recabar la opinión ciudadana en la Comunidad Autónoma del País Vasco sobre la apertura de un proceso de negociación para alcanzar la paz y la normalización política; sentencia que declara la inconstitucionalidad y consiguiente nulidad de la mencionada Ley del Parlamento Vasco.

Y la segunda es la realizada en las impugnaciones promovidas por el Gobierno de España contra diversos preceptos del Decreto del Parlamento de Canarias 95/2014, de 25 de septiembre, por el que se aprueba el Reglamento de las consultas a la ciudadanía en asuntos de interés general de competencia de la Comunidad Autónoma de Canarias, y contra el Decreto del Gobierno de Canarias 107/2014, de 2 de octubre, por el que se convoca consulta ciudadana mediante pregunta directa en el ámbito territorial de Canarias. Estas impugnaciones dieron lugar al Auto del Pleno del TC 53/2015, de 3 de marzo, por el que se mantiene la suspensión acordada en la impugnación de las disposiciones autonómicas n. ${ }^{\circ}$ 6415-2014, promovida por el Gobierno de la Nación en relación con diversos preceptos del Decreto del Parlamento de Canarias 95/2014, de 25 de septiembre, por el que se aprueba el Reglamento de las consultas a la ciudadanía en asuntos de interés general de competencia de la Comunidad Autónoma de Canarias; y al Auto TC 54/2015, de 3 de marzo, también del Pleno, por el que se acuerda la extinción de la impugnación de disposiciones autonómicas n. ${ }^{\circ}$ 6416-2014, promovida por el Gobierno de la Nación en relación con diversos preceptos del Decreto del Gobierno de Canarias 107/2014, de 2 de octubre, por el que se convoca consulta ciudadana mediante pregunta directa en el ámbito territorial de Canarias. El asunto fue finalmente resuelto por la sentencia del TC 137/2015, de 11 de junio, sobre la impugnación por el Gobierno (n. ${ }^{\circ}$ 6415-2014) contra los artículos 3 y 4 , y 9 a 26, y la disposición adicional y las disposiciones finales del Decreto del Gobierno de Canarias 95/2014, de 25 de septiembre, por el que se aprueba el Reglamento de consultas a la ciudadanía en asuntos de interés general de competencia de la Comunidad Autónoma de Canarias; y por la STC 147/2015, de 25 de junio, sobre la impugnación por el Gobierno (n. ${ }^{\circ} 6416-2014$ ), contra los apartados 1, 2, 4 y 5 del Decreto 107/2014, de 2.10.2014, del Gobierno de Canarias, por el que se convoca consulta ciudadana mediante pregunta directa en el ámbito territorial de Canarias. Sentencias que, en los dos casos, declaran la inconstitucionalidad y consiguiente nulidad del mencionado Decreto del Gobierno

de Canarias por el que se aprueba el Reglamento de consultas, y del Decreto por el que el Gobierno de Canarias convocaba la mencionada consulta ciudadana.

\section{LA DOCTRINA}

Las actuaciones del TC referidas al proceso independentista catalán y mencionadas en el apartado anterior de este trabajo, centran su doctrina jurisprudencial sustantivamente sobre cinco cuestiones: a) la soberanía de la nación española; 
b) la primacía de la Constitución Española de 1978; c) las formas de participación ciudadana y las competencias estatal y autonómica a este respecto; $d$ ) la competencia autonómica, en términos generales; y e) cuestiones de tipo adjetivo, sobre la admisibilidad y sustanciación de los recursos presentados.

De estas cinco cuestiones, tres son verdaderamente las que constituyen el punto central del conflicto y, por lo tanto, los temas sobre los que el TC ha centrado su reflexión y las decisiones finales adoptadas. Es verdad que a lo largo de este proceso político independentista, son muchas las decisiones jurisdiccionales adoptadas por el TC al respecto ( 23 en total, como se ha visto en el apartado segundo de este trabajo) y, desde luego, muchas más también las cuestiones sobre las que el TC ha formulado su doctrina. Sin embargo, no sólo es demasiado estrecho el marco de este trabajo como para poder ocuparnos con extensión de todas esas cuestiones, sino que el contenido material de las mismas no tiene siempre la misma relevancia, y muchas de ellas se refieren a temas de índole meramente adjetivo o procesal. Nos limitamos, pues, a reseñar aquí sólo la doctrina del TC sobre las tres cuestiones cardinales de todo este proceso: la afirmación de la soberanía indivisible de la nación española; la primacía de la Constitución; y las formas de participación ciudadana y las competencias estatal y autonómica a este respecto.

\section{La soberanía de la nación española}

La cuestión que se plantea aquí es verdaderamente el punto central del conflicto. No se trata sólo de decidir sobre si el pueblo catalán es o no una nación —aspecto adjetivo, más propio de la Historia o de la Ciencia Política, que del Derecho- sino de establecer si ese pueblo goza de la condición de soberano en términos jurídicos y, por ello, si puede ejercer la autodeterminación para decidir su futuro político, en el marco de la Constitución y del ordenamiento jurídico que esta preside, y que esta decisión sea organizada y guiada por las instituciones de gobierno que se derivan precisamente de la Constitución y de su Estatuto de Autonomía, aprobado este último de acuerdo con las previsiones de la primera.

El TC es muy claro y contundente al afirmar que, de acuerdo con lo establecido en el artículo 1.2 CE, la «soberanía nacional» reside en el pueblo español, del que emanan los poderes del Estado. Este precepto, que es considerado la «base de todo nuestro ordenamiento jurídico» (STC 6/1981, FJ 3), atribuye, por tanto, con carácter exclusivo, la titularidad de la soberanía nacional al pueblo español, al que se conceptúa como la «unidad ideal de imputación del poder constituyente» y, como tal, «fundamento de la Constitución y del Ordenamiento jurídico y origen de cualquier poder político». (STC 42/2014, FJ 3; que cita, además, las SSTC 6/1981, FJ 3; 12/2008, FJ 4; 13/2009, FJ 16; y 31/2010, FJ 12).

Esto viene a significar que, «si en el actual ordenamiento constitucional solo el pueblo español es soberano, y lo es de manera exclusiva e indivisible, a ningún 
otro sujeto u órgano del Estado o a ninguna fracción de ese pueblo puede un poder público atribuirle la cualidad de soberano». En este sentido, todo acto que afirme la condición de sujeto soberano como atributo del pueblo de una Comunidad Autónoma no puede dejar de suponer la «simultánea negación de la soberanía nacional que, conforme a la Constitución, reside únicamente en el conjunto del pueblo español» (STC 42/2014, FJ 3).

De acuerdo con esta visión, sostiene el TC que la unidad del sujeto soberano es el fundamento sobre el que se establece la Constitución, «mediante la que la nación misma se constituye, al propio tiempo, en Estado social y democrático de Derecho (art. 1.1 CE y, entre otras, STC 4/1981, de 2 de febrero, FJ 3)». Se trata de un Estado también «único o común para todos y en todo el territorio», lo que no excluye su articulación compuesta, o compleja, por obra del reconocimiento constitucional de autonomía a las distintas nacionalidades y regiones que, constituidas en Comunidades Autónomas en virtud de sus respectivos Estatutos, integran España (principio de unidad del Estado, deducible también del artículo 2 CE). (STC 259/2015, FJ 4, que cita SSTC 29/1986, FJ 4; 177/1990, FJ 3; 259/2015, FJ 4 y STC 247/2007, FJ 4.a).

En este sentido, es claro que la atribución de la soberanía nacional al pueblo español, en virtud del artículo 1.2 CE, y la unidad de la Nación española como fundamento de la Constitución, en virtud del artículo $2 \mathrm{CE}$, no son incompatibles con el derecho a la autonomía de las nacionalidades y regiones que la integran, sino que se encuentra integradas constitucionalmente como parte de un mismo precepto: el artículo 2 CE. Ahora bien, la autonomía «no es el resultado de un pacto entre instancias territoriales históricas que conserven unos derechos anteriores a la Constitución y superiores a ella, sino una norma del poder constituyente que se impone con fuerza vinculante general en su ámbito, sin que queden fuera de ella situaciones históricas anteriores.» (STC 259/2015, FJ 4, que cita SSTC 76/1988, FJ 3; y 247/2007, FJ 4.a).

También en este mismo sentido, el TC entiende que «autonomía no es soberanía» (STC 247/2007, FJ 4.a) y que, por tanto, la soberanía es única, no fraccionable. De ello infiere el TC que «en el marco de la Constitución, una Comunidad Autónoma no puede unilateralmente convocar un referéndum de autodeterminación para decidir sobre su integración en España [o separación de ella]». (STC 259/2015, FJ 4).

Como dice el TC, es obvio que «en tanto que realidad socio-histórica, Cataluña (y España toda) es anterior a la Constitución de 1978», sin embargo, desde el punto de vista jurídico-constitucional, el «pueblo de Cataluña» que se menciona en las resoluciones del Parlamento catalán impugnadas, es «un sujeto que se constituye en el mundo jurídico en virtud del reconocimiento constitucional (al igual que sucede con el conjunto del "pueblo español" del que, conforme al artículo 1.2 CE, "emanan todos los poderes del Estado").» (STC 259/2015, FJ 4). La cualidad de soberano del pueblo de Cataluña, pues, es inaceptable por cuanto se predica de un sujeto «creado en el marco de la Constitución, por poderes consti- 
tuidos en virtud del ejercicio del derecho a la autonomía reconocido por la Norma fundamental» (STC 259/2015, FJ 4, que cita STC 103/2008, de 11 de septiembre, FJ 4).

\section{La primacía de la Constitución}

Es ésta una cuestión sobre la que el TC se extiende en las decisiones aquí analizadas y que le resulta especialmente querida, en términos generales, como se deriva también de las múltiples sentencias en las que esta cuestión es directa o indirectamente abordada. La Constitución Española no contiene un precepto específico en el que la norma fundamental se autoproclame suprema con respecto al resto del ordenamiento jurídico, en términos literales; sí, en cambio, establece el principio general de sujeción «a la Constitución y al resto del ordenamiento jurídico» de los ciudadanos y de los poderes públicos, en su artículo 9.1, al mismo tiempo que establece que la Constitución garantiza el principio de legalidad y la jerarquía normativa en el artículo 9.3. En términos generales, pues, la primacía de la Constitución es un principio que se deriva inmediatamente del sistema de normas constitucionalmente establecido y, desde luego, del papel que la propia Constitución atribuye al TC para que la proteja de cualquier infracción de sus previsiones en el artículo 161. Es en este contexto precisamente en el que se mueve el TC cuando afirma, con todo detalle y extensión, la primacía de la norma fundamental.

De acuerdo con el TC, el «imperio de la Constitución como norma suprema» (STC 54/1983, de 21 de junio, FJ 2, y, antes aún, STC 16/1982, de 28 de abril, FJ 1), trae causa de que «la Constitución misma es fruto de la determinación de la nación soberana por medio de un sujeto unitario, el pueblo español, en el que reside aquella soberanía y del que emanan, por ello, los poderes de un Estado» (art. 1.2 CE). (STC 259/2015, FJ 4).

De la primacía constitucional, el TC deriva inmediatamente el deber de acatamiento de la norma fundamental. En este sentido, dice el TC que «recae sobre los titulares de cargos públicos un cualificado deber de acatamiento a dicha norma fundamental, que no se cifra en una necesaria adhesión ideológica a su total contenido, pero sí en el compromiso de realizar sus funciones de acuerdo con ella y en el respeto al resto del ordenamiento jurídico (en tal sentido, entre otras, SSTC 101/1983, de 18 de noviembre, FJ 3, y 122/1983, de 16 de diciembre, FJ 5).» (STC 259/2015, FJ 4). Pero no sólo eso, sino que el deber de acatamiento implica igualmente no intentar transformar las reglas de juego político y el orden jurídico existente y por medios ilegales. (SSTC 42/2014, FJ 4; 259/2015, FJ 3).

En este sentido, pues, «el planteamiento de concepciones que pretendan modificar el fundamento mismo del orden constitucional tiene cabida en nuestro ordenamiento, siempre que no se prepare o defienda a través de una actividad que 
vulnere los principios democráticos, los derechos fundamentales o el resto de los mandatos constitucionales, y el intento de su consecución efectiva se realice en el marco de los procedimientos de reforma de la Constitución, pues el respeto a esos procedimientos es, siempre y en todo caso, inexcusable» (SSTC 103/2008, FJ 4; 42/2014, FJ 4).

A mayor abundamiento, sostiene el Tribunal, «[1]a apertura de un proceso de tales características no está predeterminada en cuanto al resultado. Ahora bien, el deber de lealtad constitucional, que como este Tribunal ha señalado se traduce en un "deber de auxilio recíproco", de "recíproco apoyo y mutua lealtad", "concreción, a su vez el más amplio deber de fidelidad a la Constitución" (STC 247/2007, de 12 diciembre, FJ 4) por parte de los poderes públicos, requiere que si la Asamblea Legislativa de una Comunidad Autónoma, que tiene reconocida por la Constitución iniciativa de reforma constitucional (arts. 87.2 y 166 $\mathrm{CE}$ ), formulase una propuesta en tal sentido, el Parlamento español deberá entrar a considerarla» (STC 42/2014, FJ 4).

En definitiva, pues, «la primacía de la Constitución no debe confundirse con una exigencia de adhesión positiva a la norma fundamental, porque en nuestro ordenamiento constitucional no tiene cabida un modelo de "democracia militante", esto es, "un modelo en el que se imponga, no ya el respeto, sino la adhesión positiva al ordenamiento y, en primer lugar, a la Constitución" (STC 48/2003, FJ 7; doctrina reiterada, entre otras, en las SSTC 5/2004, de 16 de enero, FJ 17; 235/2007, FJ 4; 12/2008, FJ 6, y 31/2009, de 29 de enero, FJ 13). Este Tribunal ha reconocido que tienen cabida en nuestro ordenamiento constitucional cuantas ideas quieran defenderse y que "no existe un núcleo normativo inaccesible a los procedimientos de reforma constitucional" » (STC 42/2014, FJ 4, que cita STC 31/2009, FJ 13).

Desde otro punto de vista, la primacía de la Constitución, va inseparablemente unida al principio democrático. Como sostiene el Tribunal, «[e]l sometimiento de todos a la Constitución es "otra forma de sumisión a la voluntad popular, expresada esta vez como poder constituyente" [SSTC 108/1986, de 29 de julio, FJ 18, y 238/2012, de 13 de diciembre, FJ 6 b)]. En el Estado constitucional, el principio democrático no puede desvincularse de la primacía incondicional de la Constitución, que, como afirmó este Tribunal en la STC 42/2014, FJ 4 c), "requiere que toda decisión del poder quede, sin excepción, sujeta a la Constitución, sin que existan, para el poder público, espacios libres de la Constitución o ámbitos de inmunidad frente a ella”.» (STC 259/2015, FJ 4)

En este sentido, entiende el TC que legitimidad democrática y legalidad constitucional van inseparablemente unidas, y que la única legitimidad democrática es la que se deriva de la Constitución (STC 259/2015, FJ 5). Así, el TC no puede menos que rechazar tajantemente la contraposición que la mencionada Resolución 1/XI del Parlamento de Cataluña establece entre el «mandato democrático» que éste ha recibido en las elecciones autonómicas del 27 de septiembre de 2015, y, por tanto, su carácter «legítimo y democrático», con la 
legalidad y la legitimidad de las instituciones del Estado, en particular la del propio Tribunal Constitucional, al que se considera directamente «carente de legitimidad y competencia». Así, dice el TC «[l]a resolución 1/XI pretende, en suma, fundamentarse en un principio de legitimidad democrática del Parlamento de Cataluña, cuya formulación y consecuencias están en absoluta contradicción con la Constitución de 1978 y con el Estatuto de Autonomía de Cataluña. Ello trastoca no solo los postulados del Estado de Derecho, basado en el pleno sometimiento a la Ley y al Derecho, sino la propia legitimidad democrática del Parlamento de Cataluña, que la Constitución reconoce y ampara». Y añade, «[e]n el Estado social y democrático de Derecho configurado por la Constitución de 1978 no cabe contraponer legitimidad democrática y legalidad constitucional en detrimento de la segunda: la legitimidad de una actuación o política del poder público consiste básicamente en su conformidad a la Constitución y al ordenamiento jurídico. Sin conformidad con la Constitución no puede predicarse legitimidad alguna. En una concepción democrática del poder no hay más legitimidad que la fundada en la Constitución» (STC 259/2015, FJ 5).

Por lo demás, la fuente de legitimación de la Constitución se encuentra en el carácter democrático del poder constituyente. «El pueblo soberano, concebido como la unidad ideal de imputación del poder constituyente, ratificó en referéndum el texto acordado previamente por sus representantes políticos». La primacía incondicional de la Constitución, además, también protege el principio democrático, «pues la garantía de la integridad de la Constitución ha de ser vista, a su vez, como preservación del respeto debido a la voluntad popular, en su veste de poder constituyente, fuente de toda legitimidad jurídico-política» [STC 42/2014, FJ 4 c)]. Por ello, es misión de este Tribunal velar por que se mantenga la primacía incondicional de la Constitución, que no es más que otra forma de sumisión a la voluntad popular, expresada esta vez como poder constituyente» (STC 259/2015, FJ 5, que cita STC 108/1986, FJ 18).

Pero también, la fuente de legitimación de la Constitución se encuentra en su propio contenido. Así, «la Constitución se fundamenta en el respeto de los valores de la dignidad humana, la libertad, la igualdad, la justicia, el pluralismo político, la democracia, el Estado de Derecho y los derechos fundamentales» (STC 259/2015, FJ 5).

Entre los valores superiores que la Constitución de 1978 propugna, destaca el TC el del pluralismo político, «pieza cardinal de nuestro orden de convivencia». El pluralismo político «constituye un valor positivado. Se nutre de $-\mathrm{y}$ consiste en- contenidos y procedimientos irrenunciables que son a su vez condiciones y requisitos previamente consensuados. La Constitución proclama un mínimo de contenidos y establece unas reglas de juego insoslayables para los ciudadanos y los poderes públicos. [...] Ese marco constitucional mínimo de referencia mantiene unida a la comunidad política dentro de los parámetros del pluralismo político» (STC 259/2015, FJ 5). 
Y al pluralismo político se une, como contenido sustancial legitimador de la Constitución, el «pluralismo territorial», en los términos del Tribunal. «La indisoluble unidad de la Nación española que afirma el artículo 2 CE se combina con el reconocimiento del derecho de las nacionalidades y regiones a la autonomía. El derecho a la autonomía se encuentra así proclamado en el núcleo mismo de la Constitución junto al principio de unidad. Mediante el ejercicio de aquel derecho, la Constitución garantiza la capacidad de las Comunidades Autónomas de adoptar sus propias políticas en el marco constitucional y estatutario. Es la propia norma fundamental la que obliga a conciliar los principios de unidad y de autonomía de las nacionalidades y regiones» (STC 259/2015, FJ 5).

Finalmente, el TC ve también una fuente de legitimación en la previsión misma que la Constitución hace de un procedimiento para su reforma. Así, dice el Tribunal, «la Constitución no constituye un texto jurídico intangible e inmutable. La previsión de la reforma constitucional [...] reconoce y encauza la aspiración, plenamente legítima en el marco constitucional, dirigida a conseguir que el poder constituyente constitucionalizado en los arts. 167 y $168 \mathrm{CE}$ revise y modifique la norma fundamental. (STC 259/2015, FJ 5). En este sentido, «[1]a Constitución como ley superior no pretende para sí la condición de lex perpetua. La nuestra admite y regula, en efecto, su "revisión total" (art. 168 CE y STC 48/2003, de 12 de marzo, FJ 7). Asegura así que "sólo los ciudadanos, actuando necesariamente al final del proceso de reforma, puedan disponer del poder supremo, esto es, del poder de modificar sin límites la propia Constitución" (STC 103/2008, de 11 de septiembre, FJ 2). Todas y cada una de las determinaciones constitucionales son susceptibles de modificación, pero "siempre y cuando ello no se prepare o defienda a través de una actividad que vulnere los principios democráticos, los derechos fundamentales o el resto de los mandatos constitucionales", pero para ello es preciso que "el intento de su consecución efectiva se realice en el marco de los procedimientos de reforma de la Constitución, pues el respeto a estos procedimientos es, siempre y en todo caso, inexcusable"» (STC 259/2015, FJ 7, que cita STC 138/2015, FJ 4).

En este sentido, «[e]s plena la apertura de la norma fundamental para su revisión formal, que pueden solicitar o proponer, entre otros órganos del Estado, las asambleas de las Comunidades Autónomas (arts. 87.2 y $166 \mathrm{CE}$ )». «Ello depara la más amplia libertad para la exposición y defensa públicas de cualesquiera concepciones ideológicas, incluyendo las que "pretendan para una determinada colectividad la condición de comunidad nacional, incluso como principio desde el que procurar la conformación de una voluntad constitucionalmente legitimada para, mediante la oportuna e inexcusable reforma de la Constitución, traducir ese entendimiento en una realidad jurídica" (STC 31/2010, de 28 de junio, FJ 12). El debate público, dentro o fuera de las instituciones, sobre tales proyectos políticos o sobre cualesquiera otros que propugnaran la reforma constitucional goza, precisamente al amparo de la misma Constitución, de una irrestricta libertad. Por el contrario, la conversión de esos proyectos en normas o en 
otras determinaciones del poder público no es posible sino mediante el procedimiento de reforma constitucional. Otra cosa supondría liberar al poder público de toda sujeción a Derecho, con daño irreparable para la libertad de los ciudadanos» (STC 259/2015, FJ 7).

Y concluye el Tribunal, «[una] Cámara autonómica no puede erigirse en fuente de legitimidad jurídica y política, hasta arrogarse la potestad de vulnerar el orden constitucional que sustenta su propia autoridad. [...] el respeto a los procedimientos de reforma constitucional es inexcusable, de modo que "tratar de sortear, eludir o simplemente prescindir de esos procedimientos sería intentar una inaceptable vía de hecho (incompatible con el Estado social y democrático de Derecho que se proclama en el art. 1.1 CE) para reformar la Constitución al margen de ella o conseguir su ineficacia práctica" » (STC 259/2015, FJ 7, que cita STC 103/2008, FJ 4).

Es evidente, pues, que no hay una legitimidad democrática — ni tampoco una legalidad democrática - al margen de la prevista en la Constitución y en el ordenamiento jurídico de ella directa y coherentemente derivado, ni, desde luego, cabe su afirmación de manera contraria a los principios y preceptos constitucionales.

\section{Consultas populares y referéndum}

Siendo el objetivo de las instituciones de gobierno catalanas la convocatoria de un referéndum de autodeterminación para conseguir la independencia de Cataluña ${ }^{16}$, la cuestión que se plantea aquí es, no tanto el objetivo último que se busca — que es de carácter puramente político — sino el tipo de instrumento referendario que se pretenda emplear y su carácter jurídico; en otras palabras, si ese instrumento tiene cabida en la Constitución y, desde luego, en el Estatuto de Autonomía. Aquí, la fuente primordial, y casi exclusiva, de la doctrina constitucional son la STC 31/2015, de 25 de febrero, sobre la Ley de Cataluña 10/2014, de 26 de septiembre, de consultas populares no referendarias y otras formas de participación ciudadana, y la STC 32/2015, de 25 de febrero, sobre el Decreto 129/2014, de 27 de septiembre, del Presidente de la Generalitat de convocatoria de una consulta popular no referendaria; si bien el TC acude igualmente con fre-

16 «Referéndum» y «autodeterminación» son los términos que se emplearon inicialmente de manera explícita (i.e. Resolució 742/IX del Parlament de Catalunya, sobre l'orientació política general del Govern, 2.10.2012); luego se pasó a utilizar con mayor frecuencia la expresión «derecho a decidir» (i.e. Resolució 323/X del Parlament de Catalunya, sobre l'orientació política general del Govern, 2.10.2013), para hablar finalmente de «proceso de participación ciudadana», o de «consulta». En última instancia, el Parlamento de Cataluña ha optado por ir directamente ya, sin consulta previa alguna, a un "procés constituent ciutadà, participatiu, obert, integrador», para establecer un Estado catalán independiente en forma de república y elaborar su Constitución (Resolució 1/XI del Parlament de Catalunya, sobre l’inici del procés polític a Catalunya, 9.11.2015). 
cuencia a los argumentos ya utilizados en la STC 103/2008, de 11 de septiembre, sobre la Ley del Parlamento Vasco de 27.6.2008, de convocatoria y regulación de una consulta popular al objeto de recabar la opinión ciudadana en la Comunidad Autónoma del País Vasco sobre la apertura de un proceso de negociación para alcanzar la paz y la normalización política.

La reflexión del TC parte de la constatación de que la Constitución «admite también, como cauce de conformación y expresión de la voluntad general, la participación directa de los ciudadanos en los asuntos públicos, en "aquellos supuestos en los que la toma de decisiones políticas se realiza mediante un llamamiento directo al titular de la soberanía” (STC 119/1995, de 17 de julio, FJ 3)», si bien reafirma «el carácter extraordinario de esta forma de participación ciudadana en nuestro ordenamiento jurídico, pues "aun si se admitiera que la Ley puede ampliar los casos de participación directa, los supuestos habrían de ser, en todo caso, excepcionales en un régimen de Democracia representativa como el instaurado por nuestra Constitución, en el que priman los mecanismos de Democracia representativa sobre los de participación directa" (STC 31/2015, FFJJ 3 y 4, que cita las SSTC 119/1995, FJ 3; 76/1994, FJ 3).

$\mathrm{Y}$, tras hacer un recorrido por las formas de participación directa recogidas en la Constitución, el TC afirma que «a estas previsiones del constituyente se suman todas aquellas fórmulas de participación ciudadana que instituya el legislador ordinario - estatal o autonómico- en el marco de sus competencias (así, cuando el artículo 29.6 EAC dispone que «los ciudadanos de Cataluña tienen derecho a promover la convocatoria de consultas populares por parte de la Generalitat y los Ayuntamientos, en materia de las competencias respectivas, en la forma y las condiciones que las leyes establecen»). Pero siempre, en el bien entendido de que no son expresiones del derecho de participación que garantiza el artículo 23.1 CE, sino que obedecen a una ratio bien distinta. Se trata de manifestaciones que no son propiamente encuadrables ni en las formas de democracia representativa ni en la democracia directa, incardinándose más bien en un tertium genus que se ha denominado democracia participativa» (STC 31/2015, FJ 4, que cita STC 119/1995, FJ 6).

Por otra parte, entiende el TC que «[1]a Constitución, al referirse en el artículo 149.1.32. a a las "consultas populares por vía de referéndum" ha consentido la existencia de otras consultas populares que no fueran las referendarias, habiendo sido el legislador orgánico y estatutario el que las ha introducido en el bloque de constitucionalidad [...]. Por tanto, bajo aquella denominación genérica debe comprenderse la existencia de dos instituciones de raíz diferente: el referéndum y las consultas no referendarias» (STC 31/2015, FJ 5). «La primera es manifestación del derecho de participación política directa en los asuntos públicos (art. 23.1 CE), mientras que las segundas, en cambio, lo son del mandato dirigido a los poderes públicos de facilitar la participación de los ciudadanos en la vida política, económica, cultural y social (art. 9.2 CE y concordantes).» (STC 31/2015, FJ 5). 
En lo que se refiere específicamente al referéndum, sigue diciendo el Tribunal: «el texto constitucional contempla diversos supuestos de referéndum como fórmula de participación directa de los ciudadanos en los asuntos públicos: el referéndum consultivo sobre decisiones políticas de especial trascendencia (art. 92.1), el referéndum para la ratificación de la iniciativa en el proceso autonómico (art. 151.1 CE), el referéndum de aprobación de los Estatutos de Autonomía tramitados por la vía del artículo 151 CE (art. 151.2 CE), el referéndum para su reforma (art. 152.2 CE), el referéndum de reforma constitucional (arts. 167.3 y 168.3 CE), o la ratificación de la iniciativa para una eventual incorporación de Navarra al régimen autonómico vasco (disposición transitoria cuarta CE).» (STC 31/2015, FJ 5).

¿Cuáles son, pues, las características que distinguen al referéndum de otro tipo de consultas populares? El TC recuerda aquí especialmente la doctrina establecida en la mencionada sentencia 103/2008, de 11 de septiembre, sobre la Ley Vasca de consulta popular, de 27 de junio de 2008, y en la sentencia 31/2010, de 28 de junio, FJ 69, sobre el Estatuto de Autonomía de Cataluña de 2006, y afirma: «El referéndum es, por tanto, una especie del género "consulta popular" con la que no se recaba la opinión de cualquier colectivo sobre cualesquiera asuntos de interés público, a través de cualesquiera procedimientos, sino aquella consulta cuyo objeto se refiere estrictamente al parecer del cuerpo electoral (expresivo de la voluntad del pueblo: STC 12/2008, de 29 de enero, FJ 10), conformado y exteriorizado a través de un procedimiento electoral, esto es, basado en el censo, gestionado por la Administración electoral y asegurado con garantías jurisdiccionales específicas, siempre en relación con asuntos públicos cuya gestión, directa o indirecta, mediante el ejercicio del poder político por parte de los ciudadanos, constituye el objeto del derecho fundamental recogido por la Constitución en el artículo 23.1 (así, STC 119/1995, de 17 de julio)». (STC 31/2015, FJ 3).

Así, «[p]ara calificar una consulta como referéndum o, más precisamente, para determinar si una consulta popular se verifica "por vía de referéndum" (art. 149.1.32. ${ }^{a} \mathrm{CE}$ ) y su convocatoria requiere entonces de una autorización reservada al Estado, ha de atenderse a la identidad del sujeto consultado, de manera que siempre que éste sea el cuerpo electoral, cuya vía de manifestación propia es la de los distintos procedimientos electorales, con sus correspondientes garantías, estaremos ante una consulta referendaria.» (STC 31/2015, FJ 2). Y añade el Tribunal: «[1]a circunstancia de que no sea jurídicamente vinculante resulta de todo punto irrelevante, pues es obvio que el referéndum no se define frente a otras consultas populares por el carácter vinculante de su resultado.» (STC 31/2015, FJ 3).

Los rasgos definidores del referéndum son, pues, en primer lugar, «un llamamiento del poder público a la ciudadanía para ejercer el derecho fundamental de participación en los asuntos públicos reconocido en el artículo 23.1 CE. El destinatario de la consulta es el conjunto de ciudadanos que tienen reconocido el derecho de sufragio activo en un determinado ámbito territorial o, lo que es lo 
mismo, el cuerpo electoral» (STC 31/2015, FJ 5). El «cuerpo electoral» es, pues, el sujeto que expresa la voluntad del pueblo, dice el Tribunal, si bien «el cuerpo electoral no se confunde con el titular de la soberanía, esto es, con el pueblo español (art. 1.2 CE). Este cuerpo electoral está sometido a la Constitución y al resto del Ordenamiento jurídico (art. 9.1 CE), en tanto que el pueblo soberano es la unidad ideal de imputación del poder constituyente y como tal fundamento de la Constitución y del Ordenamiento» (STC 31/2015, FJ 5, que cita SSTC 12/2008, FJ 10; y 31/2010, FJ 6).» (STC 31/2015, FJ 5). En definitiva, dice el TC, «por cuerpo electoral debe entenderse el órgano formado por el conjunto de personas a las que se les reconoce derecho de sufragio, no en atención a sus particulares intereses, sectoriales o de grupo, sino para manifestar la voluntad general» (STC 31/2015, FJ 8).

En este sentido, pues, el referéndum es siempre una consulta general, en la medida en que se refiere - conovoca - al conjunto del electorado, bien sea el electorado del conjunto del Estado o, en su caso, el electorado de una Comunidad Autónoma. Por el contrario, las consultas sectoriales serían aquellas en las que «se recaba la opinión de cualquier colectivo sobre cualesquiera asuntos de interés público a través de cualesquiera procedimientos distintos de los que cualifican una consulta como referéndum» (SSTC 31/2010; 31/2015, FJ 6). En la misma línea, añade el Tribunal, «las consultas no referendarias recaban, en cambio, la opinión de cualquier colectivo (STC 31/2010, de 28 de junio, FJ 69), por lo que articulan "voluntades particulares o colectivas, pero no generales, esto es, no imputables al cuerpo electoral" (STC 103/2008, de 11 de septiembre, FJ 2). Frente a las formas de participación política, en las que se interviene en cuanto ciudadano (uti cives), en las consultas populares no referendarias se participa a título individual (uti singulus) o como miembro de un colectivo, sea social, económico, cultural o de otra índole (uti socius)» (STC 31/2015, FJ 5). En este sentido, pues, concluye el Tribunal, las consultas sectoriales «presuponen el llamamiento a un sujeto jurídico más restringido que el cuerpo electoral, en cuanto articulan voluntades particulares o colectivas, pero no generales, esto es, no imputables al cuerpo electoral, por lo que son cauces de participación cuya regulación por el legislador autonómico [...] resulta posible» (STC 31/2015, FJ 8).

En segundo lugar, en el referéndum, «la opinión del cuerpo electoral se expresa por medio del sufragio emitido en el curso de un proceso electoral, a fin de que el resultado de la consulta pueda jurídicamente imputarse a la voluntad general de la correspondiente comunidad política y, de este modo, considerarse una genuina manifestación del derecho fundamental de participación política reconocido en el artículo 23.1 CE». «Por esta razón — sigue diciendo el TC—, el referéndum ha de realizarse de acuerdo con los procedimientos y con las garantías que permitan a los consultados expresar su opinión mediante votación, pues sólo mediante el voto puede formarse la voluntad del cuerpo electoral (SSTC 12/2008, de 29 de enero, FJ 10; y 103/2008, de 11 de septiembre, FJ 2). Solo a través del sufragio (y no por medio de otras fórmulas de exteriorización de la opinión, como 
el ejercicio del derecho de manifestación, la aportación de firmas, sondeos de opinión o encuestas, etc.) puede quedar acreditado que el resultado de la consulta sea la fidedigna expresión de la voluntad del cuerpo electoral, de modo que las exigencias del procedimiento de celebración de referéndum deben ser entendidas como medios orientados a un fin: garantizar la realidad y veracidad del juicio emitido por el cuerpo electoral» (STC 31/2015, FJ 5).

En tercer lugar, «el régimen jurídico del referéndum está sujeto a una reserva de ley orgánica, al disponer el artículo 92.3 CE que "una ley orgánica regulará las condiciones y el procedimiento de las distintas modalidades de referéndum previstas en la Constitución". Además, el referéndum, en cuanto implica el ejercicio del derecho fundamental reconocido por el artículo 23.1 CE, está sujeto en su desarrollo a la reserva de ley orgánica prevista en el artículo 81.1 del propio texto constitucional. Concurren, por tanto, dos exigencias constitucionales de reserva de ley orgánica: una, genérica, vinculada al desarrollo de los derechos fundamentales; y, otra, específica, asociada a la institución del referéndum». Por otra parte, sigue diciendo el Tribunal, «la Constitución atribuye al Estado, como competencia exclusiva, la «autorización para la convocatoria de consultas populares por vía de referéndum» (art. 149.1.32 CE), competencia que, de conformidad con la jurisprudencia, «no puede limitarse a la autorización estatal para la convocatoria de consultas populares por vía de referéndum, sino que ha de extenderse a la entera disciplina de esa institución, esto es, a su establecimiento y regulación» (STC 31/2015, FJ 5). Esta competencia estatal ha sido desarrollada por la Ley Orgánica 2/1980, de 18 de enero, reguladora de las distintas modalidades de referéndum, la cual, según el TC, «es la llamada por el artículo 92.3 CE para regular las condiciones y el procedimiento de las distintas modalidades de referéndum previstas en la Constitución, siendo además la única Ley constitucionalmente adecuada para el cumplimiento de otra reserva, añadida a la competencial del artículo 149.1.32. ${ }^{a} \mathrm{CE}$ : la genérica del artículo $81 \mathrm{CE}$ para el desarrollo de los derechos fundamentales, en este caso el derecho de participación política reconocido en el artículo 23 CE» (STC 103/2008, de 11 de septiembre, FJ 3). Esta Ley, además, no regula otros supuestos de referéndum distintos de los contemplados en el texto constitucional. Como observa el TC, «en particular, no se mencionan otras consultas de ámbito autonómico que las previstas en los arts. 151 y $152 \mathrm{CE}$, mientras que su disposición adicional excluye del ámbito de aplicación de la Ley a las consultas municipales, remitiendo su disciplina a la legislación básica de régimen local (art. $71 \mathrm{LBRL}$ ), ámbito sobre el que también se proyecta el artículo 149.1.18. ${ }^{a} \mathrm{CE}$, que atribuye al Estado la competencia exclusiva en relación con "las bases del régimen jurídico de las Administraciones públicas".» (STC 31/2010, de 28 de junio, FJ 6).

Si la competencia referendaria, así definida, es sólo una competencia del Estado, ¿cuál es la competencia de las Comunidades Autónomas en este terreno? Las Comunidades Autónomas, como está previsto en su propios Estatutos de Autonomía, pueden convocar consultas populares sobre motivos diversos, pero 
estas consultas, precisamente porque no pueden entrar en el terreno del referéndum, están sometidas a limitaciones.

Así, como establece el TC, en primer lugar, «queda fuera de la competencia autonómica formular consultas, aun no referendarias, que incidan sobre "sobre cuestiones fundamentales resueltas con el proceso constituyente y que resultan sustraídas a la decisión de los poderes constituidos. El respeto a la Constitución impone que los proyectos de revisión del orden constituido, y especialmente de aquéllos que afectan al fundamento de la identidad del titular único de la soberanía, se sustancien abierta y directamente por la vía que la Constitución ha previsto para esos fines. No caben actuaciones por otros cauces ni de las Comunidades Autónomas ni de cualquier órgano del Estado, porque sobre todos está siempre, expresada en la decisión constituyente, la voluntad del pueblo español, titular exclusivo de la soberanía nacional, fundamento de la Constitución y origen de cualquier poder político" (STC 103/2008, de 11 de septiembre, FJ 4), y niega, por tanto, la soberanía nacional de todo el pueblo español, de la que trae causa su autonomía. Es patente, pues, que el parecer de la ciudadanía sobre tales cuestiones ha de encauzarse a través de los procedimientos constitucionales de reforma» (STC 138/2015, FJ 3). «En suma — concluye el Tribunal—, una Comunidad Autónoma no puede convocar, ni realizar actuaciones formalizadas o no jurídicamente que auspicien la convocatoria de una consulta popular, aun no referendaria, que desborde el ámbito de las competencias propias, o que incida sobre «cuestiones fundamentales resueltas con el proceso constituyente y que resultan sustraídas a la decisión de los poderes constituidos» (STC 138/2015, FJ 3).

Es claro, pues, que cuando se trata de una consulta que incide sobre cuestiones fundamentales de esa trascendencia, «[e]l respeto a la Constitución impone que los proyectos de revisión del orden constituido, y especialmente de aquéllos que afectan al fundamento de la identidad del titular único de la soberanía, se sustancien abierta y directamente por la vía que la Constitución ha previsto para esos fines. No caben actuaciones por otros cauces ni de las Comunidades Autónomas ni de cualquier órgano del Estado, porque sobre todos está siempre, expresada en la decisión constituyente, la voluntad del pueblo español, titular exclusivo de la soberanía nacional, fundamento de la Constitución y origen de cualquier poder político» (STC 138/2015, FJ 4).

En segundo lugar, «el objeto de las consultas populares tampoco puede desbordar "el ámbito de las competencias autonómicas y locales, por lo que es evidente que no puede haber afectación alguna del ámbito competencial privativo del Estado" (STC 31/2010, de 28 de junio, FJ 69), tal y como contempla el propio artículo 122 EAC.» (STC 138/2015, FJ 3).

Y, en tercer lugar, en el ámbito de las consultas locales, concurre además un límite adicional: la competencia estatal relativa a las bases del régimen jurídico de las Administraciones públicas (STC 31/2015, FJ 6).

En definitiva, el referéndum, es «una especie del género "consulta popular" con la que no se recaba la opinión de cualquier colectivo sobre cualesquiera asun- 
tos de interés público a través de cualesquiera procedimientos, sino aquella consulta cuyo objeto se refiere estrictamente al parecer del cuerpo electoral». En contraposición al referéndum, las consultas no referendarias recaban la opinión de cualquier colectivo (STC 31/2010, de 28 de junio, FJ 69), por lo que articulan «voluntades particulares o colectivas, pero no generales, esto es, no imputables al cuerpo electoral» (SSTC 103/2008; 31/2015, FJ 2).

Así, en el caso del referéndum sobre la autodeterminación de Cataluña que la Ley catalana 10/2014, de 26 de septiembre, de consultas populares no referendarias y otras formas de participación ciudadana, y el Decreto 129/2014 de 27 de septiembre, de convocatoria de una consulta popular no referendaria, pretendieron convocar, así como en el caso de la consulta popular del 9 noviembre de 2014 — «proceso de participación ciudadana»— finalmente convocada en su sustitución, se incumplieron flagrantemente las previsiones constitucionales, tanto en lo que se refiere a la materia objeto de la consulta, como en lo que se refiere a la forma o procedimiento para llevarla a cabo.

\section{CONCLUSIONES}

En definitiva, pues, de acuerdo con la doctrina jurisprudencial del TC, el conjunto de las actuaciones de la Generalitat de Cataluña conducentes a la consecución de la independencia de esta Comunidad Autónoma, así como los instrumentos utilizados hasta el presente con ese fin, no tienen cabida ni en la Constitución Española de 1978 ni en el vigente Estatuto de Autonomía que de aquélla se deriva y, en consecuencia, como ha resuelto el Tribunal, son inconstitucionales y nulos.

\section{El problema político}

Dada la posición resuelta de las instituciones catalanas, que declaran abierta y explícitamente su intención de no supeditarse «a les decisions de les institucions de l'Estat espanyol, en particular del Tribunal Constitucional ${ }^{17}$, a las que consideran carentes de legitimidad y de competencia, no puede menos que concluirse que el Estado español se encuentra aquí con un problema de inusitada relevancia, tanto de tipo histórico, como político y jurídico, de muy difícil solución, dada, además, la implicación existente de otras circunstancias de tipo sociológico y económico.

Si bien la perspectiva política transciende un poco del marco analítico en el que se incluye este trabajo, que es sustantivamente jurídico — constitucional—,

17 Resolució 1/XI del Parlament de Catalunya, sobre l'inici del procés polític a Catalunya (Butlletí Oficial del Parlament de Catalunya, XI legislatura, n. ${ }^{\circ}$ 7, 9.11.20157, p. 3).

UNED. Teoría y Realidad Constitucional, núm. 37, 2016, pp. 187-220 
no puede negarse que este problema es verdaderamente político y que, por tanto, es éste el terreno en el que va a encontrar — si cabe — su mejor solución. En este sentido, el problema se plantea porque un sector de la clase política catalana, que representa a un determinado sector de la sociedad de Cataluña, ha optado por la vía de la independencia, de la separación política de España, para la resolución de sus problemas económicos — predominantemente-, políticos y sociales, incluyendo en esto último cuestiones de tipo identitario, principalmente idiomáticas. Sin duda alguna, la solución más pertinente en este terreno es la negociación política entre las instituciones catalanas y las instituciones del Estado español. Es la primera y más obvia de las soluciones; es casi un lugar común el decirlo. Sin embargo, es evidente que, hasta el presente, la vía de la negociación viene dificultada porque una de las partes - las instituciones catalanas - insiste en la utilización de instrumentos jurídicos no previstos constitucionalmente, o la vía de hecho, mientras que la otra parte —el Gobierno del Estado- insiste en el mantenimiento incólume del ordenamiento jurídico-constitucional.

Sin embargo, tampoco puede ignorarse que quienes este problema plantean al Estado, por muy amplia que sea hoy su representación política en las instituciones catalanas, ésta apenas alcanza la mayoría absoluta en el Parlamento (53,3\% de los escaños), y no alcanza a reunir ni siquiera la mitad del voto expresado. De hecho, en las últimas tres convocatorias electorales habidas en Cataluña, coincidiendo precisamente con el momento de mayor efervescencia y radicalización del movimiento soberanista, el voto conseguido por las fuerzas separatistas que consiguieron representación parlamentaria alcanzó sólo el 45,5\% de los votos expresados en las elecciones al Parlamento Europeo del 25 de mayo de 2014; el 47,8\% en las elecciones autonómicas del 27 de septiembre de 2015; y sólo el 31,1\% en las elecciones generales del 20 de diciembre de 2015. Y si de referéndums se trata, no puede dejar de ser resaltado aquí que el referéndum sobre el Estatuto de Autonomía de 2006, cuya impugnación por diputados del PP y su posterior anulación parcial por el TC ha servido como la gran excusa, como la justificación y detonante del inicio del proceso separatista, registró una participación de sólo el 49,41\% de los censados y, si bien el «sí» al Estatuto logro reunir al 73,24\% de los votantes, la baja participación lograda hace que, en realidad, el conjunto de los votos afirmativos represente sólo el $36,17 \%$ del censo electoral. Y, en lo que se refiere a la consulta — «proceso de participación ciudadana»— del 9 de noviembre de 2015, hecha con carencia total de las garantías mínimas exigibles - como se deduce de la jurisprudencia constitucional analizada-, pero tras un enorme esfuerzo de movilización por parte de la Generalitat catalana, la participación fue sólo del 36,59\% del censo elaborado al efecto, de acuerdo con los datos de la propia Generalitat, si bien el 80,7\% de los votantes contestó «sí» a las dos preguntas que se preguntaron; es decir, «sí» a que Cataluña se convierta en Estado, $\mathrm{y}$ «sí» a que este Estado sea independiente.

Lo que estos datos revelan es que la «cuestión catalana» está políticamente sobredimensionada y que el peso real, social e institucional, de las fuerzas separa- 
tistas - tanto en las instituciones catalanas como, desde luego, en las instituciones del Estado - es mucho menor de lo que su incidencia política parece demostrar. Y ello es así, en muy buena medida, porque los partidos de ámbito nacional, fundamentalmente el PSOE y el PP, se han apoyado con frecuencia en esos partidos separatistas para gobernar, bien a través de acuerdos concretos o eventuales, bien a través de acuerdos de legislatura. Apoyo que se ha pagado en gran parte de los casos con el consentimiento, cuando no el favorecimiento o la promoción, de la actuación de estos partidos principalmente en el gobierno de Cataluña, pero también en el gobierno del País Vasco.

En definitiva, la actuación política en este terreno, si bien requiere de la negociación y del esfuerzo de entendimiento, requiere igualmente de un esfuerzo de realismo, de poner las cosas en su justo sitio y, sobre todo, de actuar sobre ese amplísimo sector de la sociedad catalana que se opone a la independencia y que supera con mucho la mitad de los ciudadanos, favoreciendo y promocionando su articulación política — hoy muy débil—, para que el diálogo y la negociación sobre el conflicto les represente también a ellos, y no sólo a la minoría separatista.

\section{2. ¿La solución jurídica?}

Pero, al lado del problema político está la posible solución jurídica. La verdad es que las posibilidades de solución del problema en este terreno son prácticamente nulas, dado que el marco constitucional — como ha demostrado la jurisprudencia constitucional aquí reseñada - es muy claro y, al mismo tiempo, estrecho, en este terreno. Todo cambio en el estatuto jurídico-político de Cataluña en el marco del sistema constitucional actual requiere un cambio - una reforma - en la misma Constitución, y ello no se puede conseguir sino con un acto de voluntad del poder constituyente; es decir, con una decisión del verdadero soberano, que, de acuerdo con el artículo 1.2 de la Constitución, es el conjunto del pueblo español, «del que emanan los poderes del Estado», como reza el mencionado precepto. Incluso en el caso de que el Estado, en el ejercicio de su competencia constitucional (art. $92 \mathrm{CE}$ ), convocase un referéndum consultivo sobre la autodeterminación de Cataluña, en última instancia, si Cataluña optase por la separación, la sustanciación de la misma requeriría una reforma total de la Constitución, de acuerdo con las previsiones del artículo $168 \mathrm{CE}$, y, por lo tanto, un pronunciamiento final del poder constituyente, del conjunto del pueblo español. Por otra parte, tanto si esta consulta se hiciese sólo en el ámbito de Cataluña, como si se hiciese en el ámbito de todo el Estado español, la consulta sería inconstitucional en razón de la materia, dado que estaría sometiendo a referéndum una materia indisponible para los poderes ordinarios del Estado, que corresponde sólo al poder constituyente, y el poder constituyente se expresa sólo a través de los procedimientos previstos de reforma constitucional. 
Ésta sería la que cabría denominar como la dimensión «positiva» de la posible solución jurídica del problema. Pero, a su lado se encuentra la dimensión «negativa» de la solución jurídica del problema; es decir, la acción coercitiva, o represiva, del Estado, tanto de carácter constitucional como de carácter penal. Dejando a un lado esta última vía, que se escapa del marco de la especialización jurídica de esta revista, es la vía constitucional la única que aquí nos interesa. En este sentido, el único cauce de este carácter que permite la Constitución es el artículo 155, que autoriza al Gobierno a adoptar «las medidas que sean necesarias», para obligar a una Comunidad Autónoma al cumplimiento forzoso de las obligaciones que la Constitución u otras leyes le impongan, en caso de que esa Comunidad las incumpliese o actuase de forma que atentase gravemente al interés general de España.

La regulación del artículo $155 \mathrm{CE}$ ha dado lugar a un debate en la doctrina científica sobre la naturaleza jurídica de esta previsión, en el sentido de determinar si ésta permite solamente lo que el artículo 37 de la Ley Fundamental de Bonn — que inspira la regulación española— denomina "coerción federal", o si, yendo más allá, permitiría también la disolución de la Generalitat o de su Parlamento, siguiendo el modelo de los sistemas que permiten la "intervención" de las entidades regionales por parte del Gobierno federal, como ocurre, por ejemplo, en los casos de la Constitución italiana (art. 126), o de la Constitución austríaca (art. 100). La verdad es que esta discusión es un poco nominalista, dado que, si bien es cierto que el artículo 155.1 habla sólo de «adoptar las medidas necesarias» para obligar a una Comunidad Autónoma al cumplimiento forzoso de sus obligaciones, o para proteger el interés general, también lo es que el concepto «medidas necesarias» es indeterminado y permite un abanico muy amplio de posibilidades de actuación por parte del Gobierno del Estado. En este sentido, nada se opondría, por ejemplo, a que el Gobierno, llegado el caso, disolviese un Parlamento autonómico y convocase nuevas elecciones, sustituyendo en esta iniciativa al propio Presidente de la Comunidad Autónoma.

En fin, la suspensión de las instituciones autónomas regionales, o la disolución de una Asamblea y la convocatoria posterior de elecciones en un territorio autónomo por parte del Gobierno central, no es algo novedoso en el Derecho comparado. Es, de hecho, la actuación que se ha seguido en Irlanda del Norte en más de una ocasión, tras la «devolución de poderes» (Northern Ireland Act 1998), cuando las dificultades del proceso de paz seguido en aquella atormentada parte del mundo impidieron formar un Gobierno estable en el terrirorio, u ocasionaron la dimisión del Gobierno en ejercicio ${ }^{18}$.

18 Si bien la suspensión más larga del gobierno autónomo de Irlanda del Norte tuvo lugar entre el 14 de octubre de 2002 y el 7 de mayo de 2007, éste fue también suspendido por el Gobierno del Londres en anteriores ocasiones: del 11 de febrero de 2000 al 30 de mayo de 2000; el 10 de agosto y el 22 de septiembre de 2001, en suspensión de sólo 24 horas. (Northern Ireland Assembly, "History of the Assembly», en: http:// www.niassembly.gov.uk/about-the-assembly/general-information/history-of-the-assembly). 


\section{Ambivalencia de la pretensión}

Por otra parte, lo que sorprende en este proceso es la ambivalencia de la actuación de la Generalitat catalana, cuyos planteamientos han sido — sonmuy radicales en sus formulaciones políticas e, incluso, osados en la utilización de los recursos procesales, pero han sido, en cambio, muy endebles en la argumentación, a veces forzados y a veces engañosos. La necesidad de utilizar un marco jurídico que es absolutamente contrario a la legalidad — constitucionalidad - de la pretensión les ha forzado, sin duda alguna, a actuar así. Pero, lo que es verdaderamente llamativo es que esta argumentación les ha haya llevado al extremo de desdecir en sus alegaciones en el procedimiento judicial lo que, en realidad, se está pretendiendo en el terreno político. Ello se manifiesta de manera paradigmática en el procedimiento ante el TC con motivo de la impugnación por el Gobierno del Estado de la mencionada Resolución del Parlamento de Cataluña 1/XI, de 9 de noviembre de 2015, sobre el inicio del proceso político en Cataluña como consecuencia de los resultados electorales del 27 de septiembre de 2015. Así, en sus alegaciones frente a la impugnación gubernamental, la Generalitat acude a la protección del TC; Tribunal al que en la misma Resolución 1/XI, considera "mancat de legitimitat $i$ de competencia», y del que, además, se pide una resolución conforme a sus intereses, cuando la Resolución 1/XI establece que «no se supeditaran a les decisions de les institucions de l'Estat espanyol, en particular del Tribunal Constitucional», al que no se perdona «la sentència de juny del 2010 sobre l'Estatut d'autonomia de Catalunya, votat prèviament pel poble en referèndum, entre altres sentències».

Y, por otra parte, la Generalitat alega ante el TC que «la resolución 1/XI, de 9 de noviembre, solo es, y no es nada más que una declaración de voluntad y de intenciones», cuando, en realidad, en la misma se afirma, de manera contundente, que «El Parlament de Catalunya declara solemnement l'inici del procés de creació d'un estat català independent en forma de república». Actuación que el Parlamento catalán realiza, en sus propios términos, «com a dipositari de la sobirania i com a expressió del poder constituent» de Cataluña. Esta resolución, pues, no es una mera declaración de intenciones; es — como entiende el TC - un verdadero acto de decisión, un hecho consumado.

\section{La doctrina jurisprudencial}

En fin, la doctrina del TC en este terreno es muy clara y contundente. Quizá la gran crítica que se le pueda hacer — en lo que se refiere a las resoluciones aquí analizadas - es que sea excesivamente reiterativa y, a veces, alambicada, precisamente en su esfuerzo por conseguir el mayor detalle y la mayor claridad interpretativa posible. Así, los argumentos se reproducen una y otra vez en los varios fundamentos jurídicos de una misma sentencia, diciendo la misma cosa varias 
veces, pero de manera diferente, o poniendo en relación diferentes preceptos o perspectivas jurídicas. Este uso exhaustivo de la argumentación, paradójicamente, complica de manera innecesaria la interpretación, al hacerla tan larga y reiterativa, dando con ello la sensación de que se dicen cosas diferentes, cuando en realidad se está diciendo lo mismo.

Por otra parte, el TC ha sido mucho más agil y decidido en esta etapa del proceso independentista que lo que lo fue en el momento de analizar el Estatuto de Autonomía catalán de 2006. En este sentido, el TC ha sido mucho más rápido en la adopción de sus decisiones, las ha adoptado todas por unanimidad y, además, sólo ha aplicado la técnica de la «interpretación conforme» en una sola ocasión. Así, no sólo todas las decisiones han sido adoptas dentro del plazo aproximado de un año, sino que en un caso — en la impugnación de la resolución del Parlamento de Cataluña 1/XI, de 9 de noviembre de 2015, sobre el inicio del proceso político en Cataluña - el TC tardó menos de un mes en decidir ${ }^{19}$, lo cual es verdaderamente una manifestación muy loable, pero insólita, de diligencia jurisdiccional.

En lo que hace referencia a la utilización del instrumento de la «interpretación conforme», el TC lo ha utilizado en la primera resolución relevante que va a adoptar en esta fase del proceso independentista. Así, la STC 42/2014, de 25 de marzo, recaída en la impugnación por el Gobierno de la Resolución del Parlamento de Cataluña 5/X, de 23 de enero de 2013, por la que se aprueba la Declaración de soberanía y del derecho a decidir del pueblo de Cataluña, el Tribunal se va a pronunciar sobre una de las cuestiones centrales de la reivindicación independentista: el denominado «derecho a decidir». En esta sentencia, el TC sostiene que el «derecho a decidir de los ciudadanos de Cataluña» tiene encaje en el marco de las previsiones constitucionales si se interpreta en el sentido que se expone en los fundamentos jurídicos 3 y 4 de esa sentencia. Es decir, de acuerdo con la visión del Tribunal, «el "derecho a decidir de los ciudadanos de Cataluña" no aparece proclamado como una manifestación de un derecho a la autodeterminación no reconocido en la Constitución, o como una atribución de soberanía no reconocida en ella, sino como una aspiración política a la que solo puede llegarse mediante un proceso ajustado a la legalidad constitucional con respeto a los principios de "legitimidad democrática", "pluralismo", y "legalidad", expresamente proclamados en la Declaración en estrecha relación con el "derecho a decidir".» (STC 42/2014, FJ 3.b).

El TC, sin embargo, se va a volver a pronunciar sobre esta cuestión en la mencionada sentencia 259/2015, de 2 de diciembre, sobre la resolución del Parlamento de Cataluña 1/XI, de 9 de noviembre de 2015, sobre el inicio del proceso político en Cataluña. En esta oportunidad, el TC entiende que la reso-

19 La impugnación del Gobierno tuvo entrada en el registro del Tribunal el día 11 de noviembre de 2015, y la sentencia 259/2015, recayó el día 2 de diciembre de 2015. 
lución impugnada - a diferencia de lo que ocurría con la Resolución del Parlamento de Cataluña 5/X, de 23 de enero de 2013- «permite entender que el Parlamento de Cataluña, al adoptarla, está excluyendo la utilización de los cauces constitucionales (art. $168 \mathrm{CE}$ ) para la conversión en un "estado independiente" [...] de lo que hoy es la Comunidad Autónoma de Cataluña. El Parlamento, en efecto, "proclama la apertura de un proceso constituyente ... para preparar las bases de la futura constitución catalana" [...]; se compromete a tramitar en determinado plazo una ley, junto a otras, de "proceso constituyente" [...]; afirma, en tanto que "depositario de la soberanía" y "expresión del poder constituyente", que en el proceso que emprende no se supeditará a las decisiones de las instituciones del Estado español y, en particular, a las de este Tribunal Constitucional [...]; por último insta al "futuro gobierno" de la Comunidad Autónoma "a cumplir exclusivamente las normas o los mandatos emanados de esta cámara" [...]» (STC 259/2015, FJ 3). Todo ello, en fin, le lleva a concluir que, en este caso, tal y como lo define la Resolción, el «derecho a decidir» supone una ruptura expresa con la legalidad constitucional del Estado y, por lo tanto no es admisible, no cabe su interpretación de manera conforme con la Constitución.

\section{La opción última}

En definitiva, pues, el proceso independentista catalán que - a efectos de este trabajo- se inicia con la Resolució 5/X del Parlament de Catalunya, per la qual s'aprova la Declaració de sobirania i del dret a decidir del poble de Catalunya, y se culmina - hasta el momento de concluir estas líneas - con la Resolució 1/XI del Parlament de Catalunya, sobre l'inici del procés polític a Catalunya com a consequiència dels resultats electorals del 27 de setembre de 2015, supone el mayor desafío político que haya recibido España desde el inicio del actual régimen democrático presidido por la Constitución Española de 1978. La reivindicación independentista — como ha explicado con detalle la jurisprudencia del TC - no tiene encaje ni solución alguna en el marco de las actuales previsiones de la Constitución. Quizá, si la exigencia de los grupos soberanistas no fuese sólo y simplemente la independencia de Cataluña, pudiera caber la negociación política y la solución jurídica, entendiendo por tal, por ejemplo, la reforma de la Constitución.

Pero, evidentemente, si el problema se sigue planteando y no se haya la solución al mismo en términos de negociación política y de solución jurídica, sólo cabe una opción: o bien se admite, sin más, la independencia de Cataluña, tal y como desean los grupos independentistas que hoy gobiernan la Generalitat catalana, y en los términos y con el programa que diseñan las resoluciones del Parlamento catalán aquí mencionadas —y anuladas por el TC—; o bien el Gobierno del Estado se opone a ello y mantiene la unidad de la nación y del Estado españo- 
les — como le obliga el artículo $97 \mathrm{CE}$ — , utilizando para ello, sin recelo alguno, todos los instrumentos que el ordenamiento jurídico y la Constitución ponen en sus manos.

TITLE: The independence process of Catalonia and the Constitutional Court doctrine: a systematic view

ABSTRACT: This article realizes a systematic organization and analysis of the decisions taken by the Spanish Constitutional Court concerning the measures adopted by the Generalitat of Catalonia conducive to the attainment of independence by this Autonomous Community since 2013. The decisions analyzed here are final judgements and procedural judicial orders that have established relevant constitutional jurisprudence, as much on substantial issues directly affected by the Catalonian independence process — the sovereignty of the Spanish nation, the primacy of the Constitution, the referendum - as on other peripheral issues. The Constitutional Court concludes that neither the mentioned activities of the Generalitat of Catalonia conducive to the attainment of independence by this Autonomous Community, nor the legal instruments used so far for this purpose may be accepted within the framework of the Spanish Constitution of 1978 and the Statute of Autonomy of Catalonia, which is a constitutional offspring.

RESUMEN: Este trabajo realiza una ordenación y un análisis sistemáticos de las decisiones adoptadas por el Tribunal Constitucional sobre el conjunto de las actuaciones de la Generalitat de Cataluña conducentes a la consecución de la independencia de esta Comunidad Autónoma, a partir del año 2013. Se trata de autos y sentencias que han producido una doctrina constitucional relevante, tanto sobre aspectos directamente afectados por el proceso independentista catalán — la soberanía de la nación española, la primacía de la Constitución, el referéndum - como con respecto a otras cuestiones tangenciales. La conclusión del Tribunal Constitucional es que ni las mencionadas actuaciones de la Generalitat de Cataluña conducentes a la consecución de la independencia de esta Comunidad Autónoma, ni los instrumentos jurídicos utilizados hasta el presente con ese fin, tienen cabida ni en la Constitución Española de 1978 ni en el vigente Estatuto de Autonomía de Cataluña que de aquélla se deriva.

KeY wORDS: Autonomy; Catalonia; public consultations; independence; Spanish nation; constitutional primacy; referendum; sovereignty; Constitutional Court.

Palabras Clave: Autonomía; Cataluña; consultas populares; independencia; nación española; primacía de la Constitución; referéndum; soberanía; Tribunal Constitucional.

FECHA DE RECEPCIÓN: 02.01.2016

FECHA DE ACEPTACIÓN: 15.01.2016 